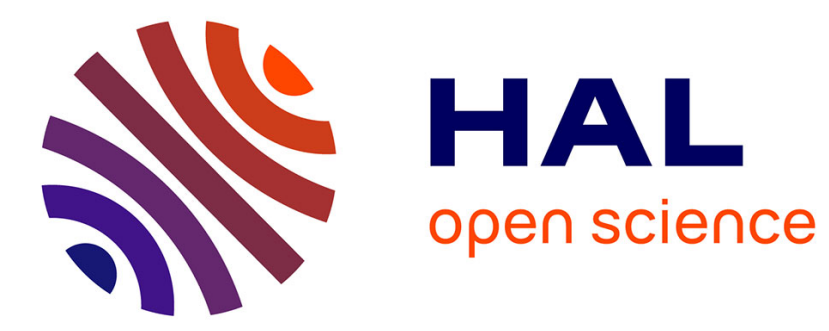

\title{
The Glutamate Hypothesis in ALS: Pathophysiology and Drug Development.
}

Hélène Blasco, Sylvie Mavel, Philippe Corcia, Paul H Gordon

\section{To cite this version:}

Hélène Blasco, Sylvie Mavel, Philippe Corcia, Paul H Gordon. The Glutamate Hypothesis in ALS: Pathophysiology and Drug Development.. Current Medicinal Chemistry, 2014, 21, pp.3551-75. hal01076261

\section{HAL Id: hal-01076261 https://hal.science/hal-01076261}

Submitted on 17 Jul 2018

HAL is a multi-disciplinary open access archive for the deposit and dissemination of scientific research documents, whether they are published or not. The documents may come from teaching and research institutions in France or abroad, or from public or private research centers.
L'archive ouverte pluridisciplinaire HAL, est destinée au dépôt et à la diffusion de documents scientifiques de niveau recherche, publiés ou non, émanant des établissements d'enseignement et de recherche français ou étrangers, des laboratoires publics ou privés. 


\title{
The Glutamate Hypothesis in ALS: Pathophysiology and Drug Develop- ment
}

\author{
H. Blasco ${ }^{* 1,2}$, S. Mavel ${ }^{2}$, P. Corcia ${ }^{2,3}$ and P.H. Gordon*,4 \\ ${ }^{I}$ CHRU Tours, laboratoire de Biochimie et Biologie Moléculaire, Tours, France; ${ }^{2}$ INSERM U930, Université François- \\ Rabelais, Tours, France; ${ }^{3}$ Centre SLA, CHRU de Tours, Tours, France; ${ }^{4}$ Indian Health Service, Northern Navajo Medi- \\ cal Center, Shiprock, NM, USA
}

\begin{abstract}
Amyotrophic lateral sclerosis (ALS) is an age-related neurodegenerative disorder that is believed to have complex genetic and environmental influences in the pathogenesis, but etiologies are unidentified for most patients. Until the major causes are better defined, drug development is directed at downstream pathophysiological mechanisms, themselves incompletely understood. For nearly 30 years, glutamate-induced excitotoxicity has lain at the core of theories behind the spiraling events, including mitochondrial dysfunction, oxidative stress, and protein aggregation, that lead to neurodegenerative cell death. One drug, riluzole, which possesses anti-glutamatergic properties, is approved as neuroprotective for ALS. Following the achievement of the riluzole trials, numerous other agents with similar mechanisms have been tested without success. This article provides an overview of excitotoxicity in ALS, focusing on the events that contribute to excess glutamate, how the excess might damage nerve cells, and how this information is being harnessed in the development of potential new neuroprotective agents. The work highlights clinical trials of drugs that have targeted the glutamate system, comments on the potential role of glutamate as a biomarker and concludes with a section on future directions for the field. As research uncovers elusive etiologies and brings clarity to pathophysiological mechanisms, the success of new interventions will increasingly depend on the design of agents that target particular mechanisms for specific individuals. The heady future of personalized drug regimens for ALS rests with medicinal chemists, the scientists whose ideas and work produce these designer drugs.
\end{abstract}

Keywords: Amyotrophic lateral sclerosis, neurodegeneration, glutamate, pathophysiology, diagnosis, treatment.

\section{BACKGROUND}

The predominant feature of amyotrophic lateral sclerosis (ALS), motor neuron degeneration in the brain and spinal cord [1] and the resulting weakness of voluntary muscles, is so consequential that most patients die in less than three years from symptom-onset and less than two years from diagnosis [2]. Drug development has yielded few successes and the prognosis has not changed meaningfully since the first reports, nearly 150 years ago.

ALS is considered a syndrome of different disorders that arise from the interaction of diverse genetic and environmental factors, perhaps acting in concert over a lifetime [1, 2]. Like other neurodegenerative disorders, the clinical and pathological features of ALS begin focally and then spread relentlessly; many patients not only develop global weakness but also extra-motor phenomena, including cognitive impairment [3]. The disease physiology is now known to involve surrounding support cells, particularly astrocytes, as well as motor neurons.

\footnotetext{
*Address correspondence to these authors at the Division of Neurology, Northern Navajo Medical Center, Shiprock, NM 87420, USA; Tel: 505-3686339; Fax: 505-368-7078; E-mail: paul.gordon@ihs.gov and Laboratoire de Biochimie et Biologie Moléculaire, CHRU de Tours, Tours, INSERM U930, Université François Rabelais, Tours, France; Tel: + 332474737 95; Fax:+332474786 13; E-mail: helene.blasco@univ-tours.fr
}

In the middle of the $19^{\text {th }}$ Century, Jean-Martin Charcot established the enduring foundation of the new field of neurology by characterizing diseases using a technique that he termed the clinical-anatomic method, which contextualized clinical phenomenology with pathological findings at postmortem examination [4]. The breadth of Charcot's contributions, which is immense, includes the delineation of motor neuron diseases. Charcot classified progressive muscular atrophy as a disease of lower motor neurons and not muscle, primary lateral sclerosis as a disorder of upper motor neurons and then ALS as affecting both upper and lower motor neurons [5]. Charcot and his contemporaries described the progressive motor weakness, limited prognosis, changes in cognition and, pathologically, loss of motor neurons that exemplify the disorder today.

For the next 100 years, neurology was largely a descriptive field, defining diseases based on their pathological underpinnings and bringing better understanding to enigmatic neurological conditions. Expanded knowledge eventually led to the emergence of new treatments. In the 1960s, the dramatic improvement in symptoms of Parkinson disease following administration of levodopa changed how neurodegenerative disorders were perceived [6]. Suddenly these most intransigent of diseases seemed within the grasp of therapeutic development. But neuroprotective agents that could alter not just symptoms but the underlying disease progression seemed a distant hope, in large part because, as 
Charcot noted in his initial descriptions, the great challenge of neurodegenerative diseases lies in the hidden secret of their etiologies.

By 1987, abnormal levels of glutamate, the most abundant excitatory neurotransmitter, were identified in plasma [7] and then pathological specimens [8] of patients with ALS and the notion of excitotoxicity as central to neurodegeneration, with glutamate as the pivotal character, was born. Biochemical studies found high glutamate levels in ALS cerebrospinal fluid, which was subsequently shown to be toxic to neurons in culture [9]. Motor neurons were found to be especially susceptible to glutamate-induced excitotoxicity because of their large size, high expression of glutamate receptors and low calcium buffering capacity. When evidence was uncovered of altered expression of the glial glutamate transporter excitatory amino acid transporter 2 (EAAT2) $[10,11]$, which is responsible for removal of glutamate from the synaptic cleft, the link between excitotoxicity, cell death, and heightened levels of synaptic glutamate was closed.

In 1995, the field seemed poised for another transformation, when riluzole, possessing purported anti-glutamatergic properties, proved to be neuroprotective for ALS and was approved by regulatory agencies as the first disease modifying treatment for a neurodegenerative disorder [12]. Recently memantine, also acting on the glutamate system, was shown to be neuroprotective for Alzheimer disease, another agerelated neurodegenerative disorder [13]. In 2003, the discovery, in a high throughput screening initiative, that betalactam antibiotics increased expression of EAAT2 $[10,11]$ set in motion one of the largest translational projects in ALS to date, culminating, ten years later, in a series of human trials. Progress continues, but in the 18 years since riluzole was approved, numerous other agents, including those acting to reduce the effects of glutamate, have been tested in ALS without success, placing great emphasis on the search for etiologies and elucidation of cellular events that lead to nerve cell death.

Prominent among reasons for the long drought of unsuccessful trials in ALS is the absence of biomarkers. Time from symptom onset to diagnosis is more than a year, limiting the patient pool for participation in clinical trials and precluding the ability to intervene early in the disease course. Clinical measures of disease progression have high variance so that treatment trials must be large and long in order to reliably detect changes. Most phase III trials take years to complete, which, in combination with few potential patient participants, greatly restricts the number of drugs that can be tested at any time. The inability, to date, to directly measure the biological effect of a drug has made definition of dose and regimen for neuroprotection particularly problematic. Reliable, measurable indicators of disease physiology could improve patient care by heightening diagnostic sensitivity, and efficiency of clinical trials through inclusion of endpoints that more sensitively measure progression and drug effect.

Glutamate is central to current hypotheses regarding cell death, and by extension, to the development of biomarkers and new drugs for ALS. The exact place for excitotoxicity, related to the cause, a downstream event, or peripheral to other key processes, is a matter of intense research [14]. This article reviews the mechanisms through which glutamate might contribute to the demise of motor neurons and how this knowledge could be harnessed to develop new neuroprotective agents for a disorder that has resisted drug discovery since Charcot's first descriptions, over 140 years ago.

\subsection{Role of Glutamate in Health and Disease}

Glutamate is an amino acid and the principal excitatory neurotransmitter in the central nervous system. It functions in processes as diverse as synaptogenesis, synaptic plasticity, long-term potentiation and energetic metabolism [15-17]. Glutamate is involved in cognitive functions such as memory and learning through synaptic plasticity, and also regulates growth cones as well as synaptogenesis during brain development.

Glutamate, which is stored in vesicles in presynaptic neurons and is released in response to membrane depolarization, activates post-synaptic cells via glutamate receptors. Glutamate transporters, found in neuronal and glial cell membranes, remove glutamate from the extracellular space.

Excess glutamate appears to drive excitotoxicity through heightened flow of calcium ions into neurons. High concentrations of cytosolic $\mathrm{Ca}^{2+}$ activates enzymes, including phospholipases, endonucleases, and proteases, that damage components of the cytoskeleton, cell membrane, mitochondria, and DNA, leading eventually to death of the cell, in part, through apoptotic pathways.

\subsubsection{Glutamate Receptors}

Once released into the synapse, the wide-ranging effects of glutamate are mediated through one of two receptor types, ionotropic or metabotropic receptors, whose unique electrophysiological, biochemical and pharmacological properties can be characterized in the laboratory by molecular cloning experiments [18-22].

\subsubsection{Ionotropic Receptors}

Ionotropic receptors are ligand-gated ion channels that include $\alpha$-amino-3-hydroxy-5-isoxazole propionate (AM PA), $N$-methyl-D-aspartate (NMDA) and kainate receptors. AMPA and NMDA receptors are largely responsible for calcium flux across neuronal cell membranes.

Functional AMPA receptors, ionotropic transmembrane proteins that mediate fast synaptic transmission, are the most common receptors found in the brain. They are homo or hetero-oligomeric, with the latter being composed of four subunits (GluR1-GluR4). GluR2 contains one re-entrant loop within the membrane that is the site for glutamine/arginine RNA editing and the regulation of calcium flux. AMPA receptors that facilitate fast excitatory synaptic neurotransmission were initially considered impermeable to calcium, but it has been demonstrated that those receptors possessing the GluR2 subunit are an important hub of calcium permeability $[23,24]$. Modifications to the expression or posttranscriptional editing of GluR2 can result in higher or lower concentrations of calcium entry into cells. In motor neurons, calcium permeability via the AMPA receptor is determined, in part, by perisynaptic astrocytes, which release factors that activate the GluR2 subunit [25]. Motor neurons appear to be 
particularly vulnerable to excitotoxicity because they contain a high concentrations of calcium permeable AMPA receptors and low quantities of $\mathrm{Ca}^{2+}$ buffering proteins [25].

NMDA receptors, which mediate synaptic plasticity and late components of excitotoxicity [26, 27], are composed of GluN1 (NR1) and GluN2 (NR2) subunits, the latter having four subvariants labelled NR2A, NR2B, NR2C and NR2D. Glutamate binds the NR2 subunit, accelerating entry of calcium and sodium ions into, and flow of potassium out of the cell. At resting membrane potential, magnesium ion binds to a site within the channel pore, blocking flow through the channel. Membrane depolarization leads to expulsion of $\mathrm{Mg}^{2+}$ and allows passage of ions through the channel. The characteristics of the Glu2 (NR2) subunit influence properties of the NMDA receptor, including agonist affinity, calcium permeability, deactivation kinetics, single-channel conductance, and extent of $\mathrm{Mg}^{2+}$-induced channel blockade [26, 27]. Inhibition of the NMDA receptor by $\mathrm{Mg}^{2+}$ appears to be weaker in NR1/2C and NR1/2D receptors than in NR1/2A or NR1/2B receptors [28-30]. Calcium flux through NMDA receptors is considered central to synaptic plasticity, the cellular mechanism underlying learning and memory.

Kainate receptors are tetrameric combinations of a number of subunits (GluK1-GluK5). They mediate pre- and postsynaptic actions of glutamate [31], but do not have a defined role in the pathophysiology of central nervous system diseases, including ALS, and so will not be detailed further in this review.

\subsubsection{Metabotropic Receptors}

Metabotropic glutamate receptors (mGluR) are coupled to $\mathrm{G}$ proteins $(\alpha, \beta, \gamma)$ and influence second messenger processes with functions as diverse as learning, memory, anxiety and pain. Eight heterogeneous receptors are classified into three groups: mGlu1R and mGlu5R comprise group I; mGlu2R and mGlu3R group II and mGlu4R and mGlu6-8R group III. These receptors are localized to both pre-and postsynaptic sites throughout the brain. mGluRs appear to modulate excitotoxicity in motor neurons by, as yet, not fully elucidated mechanisms $[32,33]$.

\subsubsection{Glutamate Transporters}

A process of high-affinity glutamate uptake into neurons and glial cells maintains low extracellular levels of glutamate and avoids receptor over-activation [34]. The transporters, termed excitatory amino acid transporter 1-5 (EAAT1-5), along with the co-transporters symport and antiport, constitute the major mechanism for synaptic clearance of glutamate [35]. EAATs are localized to the membranes of both neurons and glia. Among the five members of the EAAT family, EAAT2 (GLT-1: mouse analog of EAAT2), which is the most abundant transporter, is present exclusively on astrocytes and has a key role in the clearance of glutamate from the synapse of motor neurons. Additional research is needed to better understand the function of other EAATs in the central nervous system.

Normally, membrane depolarization and transient elevation of intracellular $\mathrm{Ca}^{2+}$ generated by activation of both $\mathrm{Na}^{+}$ and $\mathrm{Ca}^{2+}$ voltage-gated channels initiate physiological processes such as the action potential and its propagation, synap- tic transmission, and excitation-contraction coupling, which themselves regulate the physiological release of glutamate [36]. Transporters then remove glutamate from synapse as outlined above.

\subsubsection{Excitotoxicity}

\subsubsection{Deregulation of Synaptic Glutamate Pathways}

Several lines of evidence have linked alterations in glutamate handling to the pathophysiology of ALS. Deficient editing of the GluR2 AMPA receptor subunit occurs in motor neurons of people with ALS [37]; diminished functional transport of glutamate and reduced EAAT2 immunoreactivity have been described in post mortem tissue from ALS patients $[8,38]$; and depletion of EAAT2 in transgenic mice leads directly to neuronal death [39].

A connection between mutant superoxide dismutase 1 (mSOD1), an autosomal dominantly inherited mutation that causes some forms of familial ALS, and abnormalities in EAAT2 has also been shown. mSOD1 appears to both sensitize the AMPA receptor to glutamatergic stimulation [40], and inactivate EAAT2 in the presence of hydrogen peroxide [41]. Studies in the mSOD1 transgenic (G93A) mouse model of ALS [42, 43] demonstrate that loss of EAAT2 alone contributes to disease progression in mice. Rats carrying mSOD1 show reduced synaptosomal glutamate uptake and increased extracellular levels of glutamate [44, 45]. EAAT2 expression is reduced in the presymptomatic stages and abolished completely by the end stage of the disease in some transgenic models [45]. Levels are reduced in spinal cord by approximately $50 \%$ in advanced-stage mice possessing the G85R SOD1 mutation [46]. Overexpression of EAAT2 in mSOD1 G93A mice may be neuroprotective, delaying the onset of motor deficits and reducing activation of caspase-3, a potent promoter of apoptotic cell death pathways [43].

Metabotropic Glu1-5 autoreceptors produce altered glutamate release in G93A mice, consistent with an involvement in excitotoxicity [47]. Moreover T-lymphocytes obtained from ALS patients have reduced mGlu2 receptor levels [48]. Expression of metabotropic glutamate receptors is also altered in ALS. Increased levels of group I, II, and III mGlu in astrocytes and reduced levels of group II mGlu in neurons have been reported in ALS patients [49]. Astrocytes expressing mSOD1 seem highly vulnerable to glutamate-induced excitotoxicity mediated by metabotropic receptors [50].

\subsubsection{Glutamate as a Biomarker}

Measurable indicators of biological activity are urgently needed in ALS. Based on the hypothesis of glutamatemediated excitotoxicity in ALS, numerous studies have evaluated the potential for this amino-acid to act as a biomarker, either in establishing the diagnosis or as a measure of disease progression. A central role of glutamate-provoked excitotoxicity in the pathophysiology of ALS is paralleled, in some studies, by higher-than-normal levels of glutamate and $\mathrm{N}$-acetyl-aspartyl glutamate in cerebrospinal fluid (CSF) of ALS patients [7, 51-53]. Between $40 \%$ and $75 \%$ of patients with sporadic ALS (SALS) are estimated to have defects in glutamate transport leading to excessive extracellular glutamate levels [54]. Deregulation of glutamate metabolism may be a central cause; some studies suggest that glutamate con- 
centrations in people with ALS are normal at resting state but increase after an oral intake of glutamate [55]. However, data are inconsistent and other laboratories have found no changes in glutamate concentrations in blood or CSF [56, 57]. Metabolomics studies are also conflicting, showing decreased glutamate concentrations in blood and CSF $[58,59]$ or increases in CSF [60].

Glutamate could also be used, in theory, to assess drug efficacy. One of the principle barriers to the development of glutamate as a biomarker in ALS, however, is that levels in CSF or blood may not reflect levels in the synapse capable of over-activating glutamate receptors. Concentrations appear to vary with disease stage and could vary depending on the underlying etiology. More research is needed to determine measureable glutamate levels in different tissues at various stages of the disease before the potential for glutamate to act as a biomarker in ALS is fully realized.

\subsubsection{Other Mechanisms Involved in Excitotoxicity}

D-serine is a co-agonist at the glycine site of the NMDA receptor. Increased concentrations of this amino-acid could, in theory, induce excitotoxicity, and some data suggest that Dserine levels may be elevated in ALS patients as well as animal models $[61,62]$. Mutations in the D-amino acid oxidase $(D A A O)$ gene, which prevent the breakdown of D-serine, are implicated in some forms of familial ALS (FALS) [63].

\subsubsection{Mechanisms of Excitotoxic Damage to Neurons}

Intracellular glutamate released from damaged neurons contributes to over-activation of glutamate receptors and to spiralling toxic events in and around motor neurons. Overactivation of glutamate receptors leads to excessive synaptic transmission and substantial influx of calcium into neurons. Elevated cytoplasmic calcium concentrations are deleterious to nerve cells through a variety of mechanisms. Chronic calcium overload leads to depolarization and to the generation of reactive oxygen species, which cause widespread damage to cellular structures. Excess intracellular calcium may damage mitochondria, resulting in disturbances in function of the respiratory chain that are associated with cellular energy depletion, and further contributing to the production of free radicals [64-66]. Moreover, depleted intraluminal calcium in endoplasmic reticulum (ER) resulting from calcium shifts could induce ER proteins to misfold and contribute to aggregated cellular proteins seen in ALS [67].

When the calcium-buffering capacity of a cell is exceeded, high concentrations of calcium also over-activate calcium-dependant intracellular enzymes, including lipases, phospholipases, proteases, endonucleases, protein phosphatases, protein kinase $\mathrm{C}$, xanthine oxidase and nitric oxide synthase, which further disrupt normal neuronal function. These escalating interwoven events lead eventually to energetic depletion, irreparable damage to cellular constituents and activation of pro-apoptotic and other enzymes that promote programmed cell death.

\subsection{Glutamate as Potential Target for Drug Development in ALS}

The quest for new treatments is of intense to patients, ALS researchers, and researchers in other fields. In 2013, a search of Web of Science ${ }^{\circledR}$ using the term "treatments for amyotrophic lateral sclerosis" yielded 3,162 articles. Limiting the search to the year 2000, the same keywords produced 90 articles; in 2006, 170 articles; and in 2012, 300 articles. New treatments are being tested at ALS centers worldwide. Prior to publication of this article, there were 89 open clinical trials listed on www.clinicaltrials.gov, an international trial registry, but only a small number were testing efficacy of a neuroprotective agent.

The approval of riluzole in 1995 led to great expectations in the field and was quickly followed by trials of other drugs with antiglutamatergic properties, most of which were already approved as anti-epileptic medications. (Fig. 1) shows the principal molecules targeting glutamate pathways that have been tested in ALS (Fig. 1). To the great disappointment of the ALS community, every trial since 1995 has produced a negative result, including those of drugs considered to have a mechanism similar to that of riluzole.

There is probably not a single explanation for the, now, two decades-long stagnation. Some reports of animal studies may have been overly optimistic [68], the best dose of a medication for neuroprotection has been especially difficult to find [69] and identification of efficient designs as well as solid outcome measures has required trial and error [70].

A key problem in the development of anti-glutamatergic therapies for ALS is the number of different receptors and transporter subtypes implicated in the disease. Different etiologies and disease stages could produce a moving target for intervention; a single agent might not interact with the correct target at every disease stage. A related explanation for the run of negative clinical trials to date is that drugs have been selected empirically based on global anti-glutamatergic properties rather than through design, aimed to target a specific component of the glutamate system identified as abnormal in ALS.

\subsubsection{Glutamate Receptors as Targets for Therapeutic Drug Development}

RNA editing, one possible target for intervention, could have an important role in preventing cell death through modulation of calcium permeability at AMPA receptors [71]. RNA editing is recognized as a potential target for drug discovery at different diseases, but, so far, few studies have been reported [72]. Therapies that correct aberrant splicing of mRNA transcripts using splice-site-directed oligonucleotides are being tested in clinical trials of genetic disorders such as Duchenne muscular dystrophy [73]. Transcript diversity offers new opportunities for drug design and development of new therapies. Alterations to receptors and channels made through RNA editing could change their function and act as a target for therapies in a variety of brain disorders [74]. Modifications to RNA nucleotide sequences that make up the serotonin $5 \mathrm{HT} 2 \mathrm{C}$ receptor are being used to regulate cell signalling and drug responses [75]. A few agents that inhibit RNA editing enzymes have been identified [76, 77]. High-throughput sequencing techniques could be used to search for new RNA transcripts and protein isoforms, with applications in neuromuscular and other neurological disorders. 


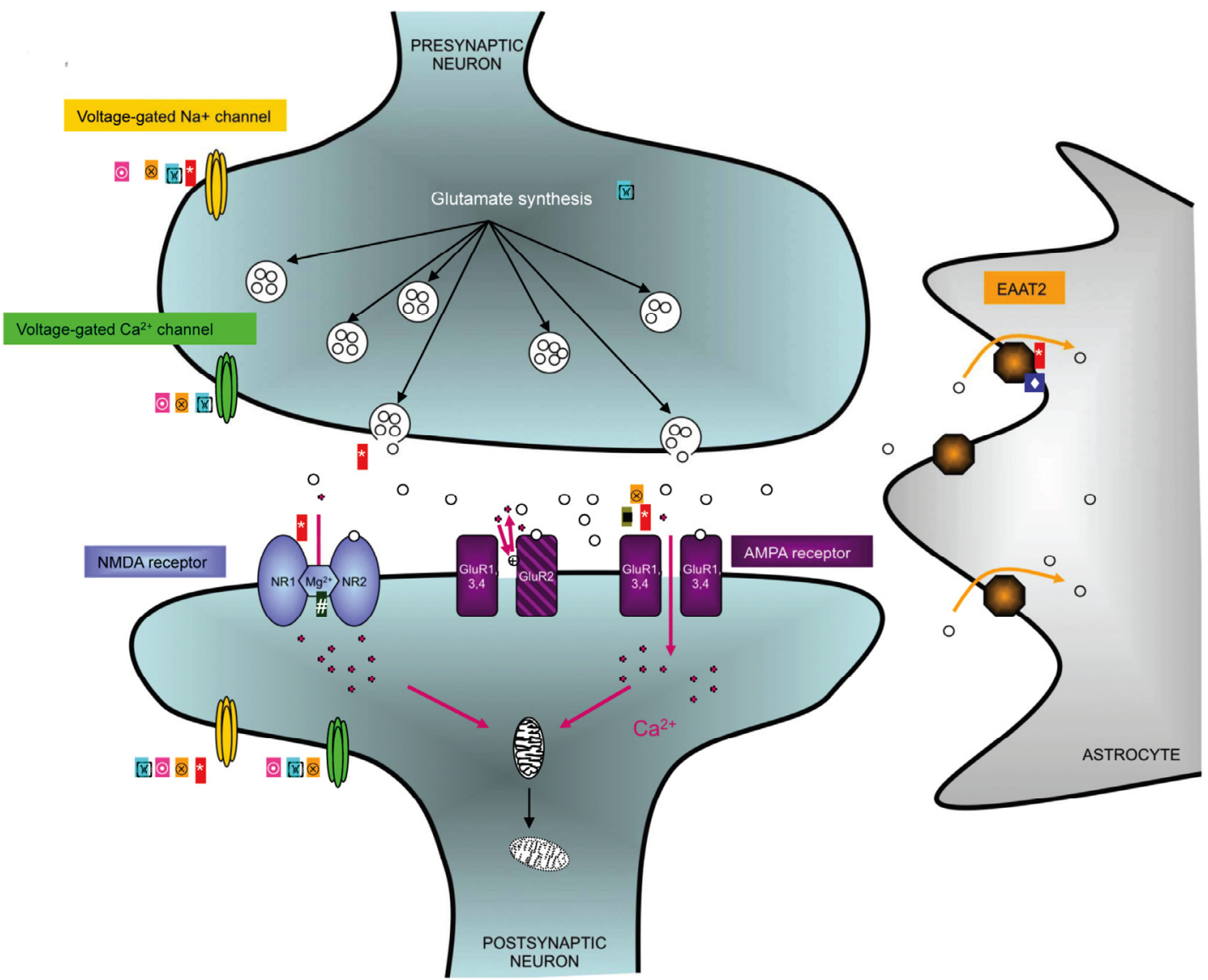

Fig. (1). Principal mechanisms of action of antiglutamatergic drugs used in ALS Lamotrigine $\odot$ Topirmate $\otimes$, Ceftriaxone $\bullet$ Riluzole $*$ Nemantine \#, Talampanelם, Gabapentin

Genetic transcript diversity is an important consideration in drug design. Antidepressants, for example, enhance GluR2 Q/R site-editing in a modified HeLa cell line expressing half-edited GluR2 pre-mRNA, probably by upregulating expression of ADAR2 (adenosine deaminase that acts on RNA) mRNA [78]. This strategy needs to be developed further but could, in theory, be used to examine efficacy of antidepressants for ALS in vivo.

Therapeutic intervention through modulation of NMDA receptors could be directed at the primary transmitter site (through competitive antagonism of the receptor), the phencyclidine site located inside the cation channel (through noncompetitive antagonism), the polyamine modulatory site or the strychnine-insensitive, coagonistic glycine site. Because NMDA receptors play a crucial role in various forms of synaptic plasticity $[79,80]$, a challenge is to develop antagonists that prevent the pathological activation of NMDA receptors while permitting their normal physiological activity. Extensive preclinical development is needed to define the correct mechanistic target, as well as timing and dose of any new agent.

\subsubsection{Glutamate Transporters as Targets for Therapeutic Drug Development}

Activators of EAAT2 could be used to reduce concentrations of glutamate in the synapse and ameliorate the excitotoxic effects of glutamate [81]. Compounds that upregulate
EAAT2 activity or increase the expression of the protein are one approach [82]. Of only a few agents described that enhance the activity of EAAT2, parawixin1, a compound isolated from spider venom, [83] was reported to be a positive and selective allosteric modulator of EAAT2 [84], but the last published investigation of this agent was in 2007. The compounds discussed in this section are shown in (Fig. 2).

A tactic for increasing the expression of the transporter is via amplified translation of EAAT2 mRNA [81]. Small molecules can be screened for effects on EAAT2 mRNA using an enzyme-linked immunosorbent assay (ELISA)based high throughput screen for EAAT2 protein expression. The chemical structures of compounds that affect EAAT2 mRNA have been optimized by pharmacomodulation and new lead compounds described [85]. Structure-activity studies (SAR) have identified the thioether and pyridazine moieties as important modulators of EAAT2 protein levels. Promising results in cell model experiments suggest that these compounds are suitable for further development, likely in animal models as a next step [85]. Of 140,000 compounds screened in a cell-based high throughput model, optimized for ELISA testing in primary astrocytes [81], two series of compounds were selected (with a half maximal effective concentration $\mathrm{EC}_{50}<1 \mu \mathrm{M}$, derivatives 1) for additional in vivo and in vitro profiling studies [85]. One thiopyridazine derivative (LDN-212320, compound $\mathbf{1}, \mathrm{n}=1, \mathrm{R}^{1}, \mathrm{R}^{2}=\mathrm{H}$, $\mathrm{R}^{3}=\mathrm{CH}_{3}$ ) was found to increase EAAT2 protein levels in astrocytes [86]. 


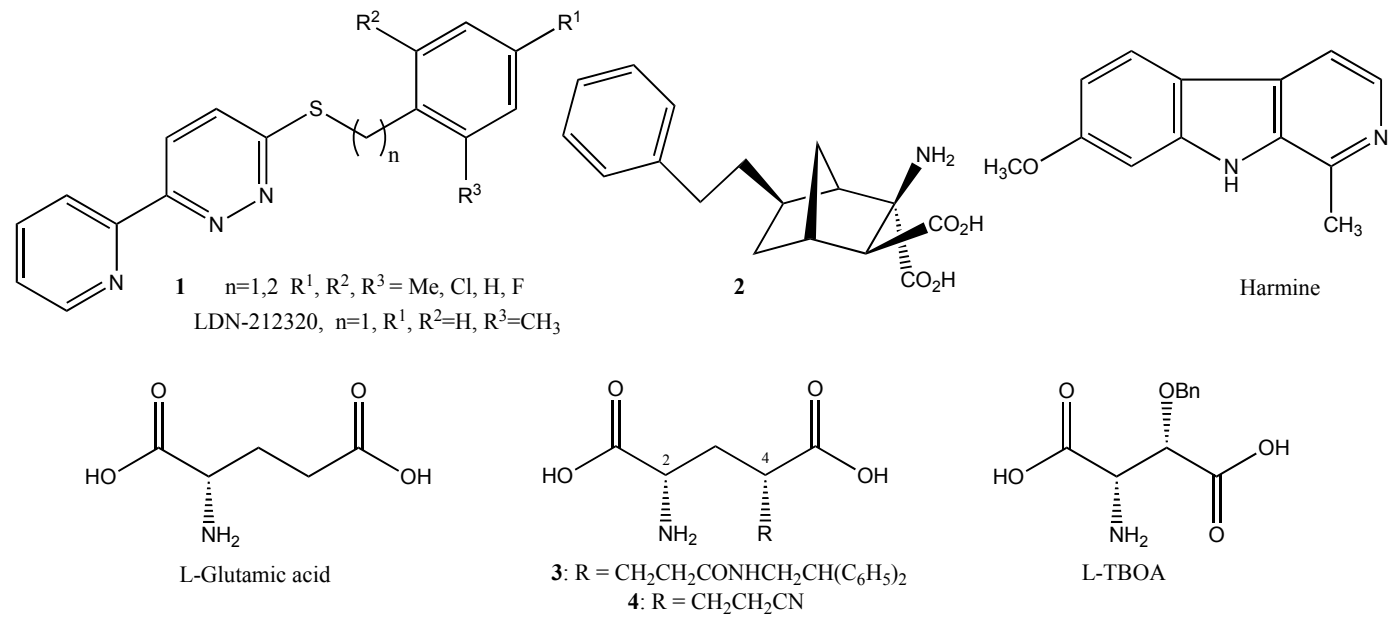

Fig. (2). Chemical structures of original scaffold and analogues of L-Glu, ligands of EAATs.

Virtual ligand screening based on high-throughput docking is a technology used to select lead compounds based on receptor structure. This technique estimates the virtual binding energy of a compound to the binding-site requirements of a protein. Docking and screening procedures are being used to select small sets of likely therapeutic candidates from large libraries of compounds. A screening initiative using virtual high throughput docking on a glutamate binding site of the glutamate transporter homologue from pyrococcus horikoshii (protein data bank PDB code: 1XFH), [87] yielded another promising compound (compound 2, half maximal inhibitory concentration $\mathrm{IC}_{50}=1.4 \mu \mathrm{M}$ toward GLT-1, the rodent homologue of EAAT2), which could have the aromatic cycle optimized by addition of diverse substituents.

A screen of 1040 FDA approved compounds and natural products identified harmine, a natural $\beta$-carbilone alkaloid as one activator of an EAAT2 promoter [87]. Harmine also induced GLT-1 expression and glutamate transporter activity in an animal model, making it a lead compound in the approach to pharmacomodulation of glutamate through upregulation of EAAT2.

The involvement of mammalian target of rapamycin (mTOR) signaling in the astrocytic regulation of EAAT2 has also been examined [88], and could prove to be another choice for the design of new structures through docking studies.

\subsubsection{Others}

Diverse experiments have been conducted with the aim of identifying a compound that selectively inhibits EAAT2 without impacting function of other EAATs or glutamate receptors (structures illustrated in Fig. 2). Several studies $[89,90]$ evaluated analogues of endogenous glutamic acid (L-Glu, (S)-2-aminopentanedioic acid,) [89, 90]. Among ten Glu-analogues assessed for their affinities for human EAAT1-3, enantiomer 3 showed selectivity for EAAT2 $\left(\mathrm{IC}_{50}\right.$ of $75 \mu \mathrm{M}$ for EAAT2, compared to $\mathrm{IC}_{50}>1000 \mu \mathrm{M}$ for EAAT1 and 3), but a lower affinity for the reference competitive, non-transportable EAAT inhibitor, DL-TBOA. These experiments highlight that extending the R side chain (derivatives 3) results in a selective EAAT2 inhibitor with low affinity for all of the ionotropic GluRs [90, 91]. Re- cently, other glutamate analogues were also characterized pharmacologically using a $\left[{ }^{3} \mathrm{H}\right]-\mathrm{D}$-aspartate uptake assay in HEK293 cells expressing human EAAT1,2,3 subtypes [92]. From these experiments, compound $\mathbf{4}$ showed selectivity for EAAT2 over EAAT1 and EAAT3 $\left(\mathrm{IC}_{50}\right.$ of $24 \mu \mathrm{M}$ at EAAT2). A comparison to previously reported EAAT inhibitory profiles from a large number of L-2,4-syn-Glu analogues (analogues of derivative 3) suggested that the observed preference for EAAT2 is a characteristic of this class of compounds, although the structural basis for the trend was not yet described [93].

Voltage gated- $\mathrm{Na}^{+}$and $\mathrm{Ca}^{2+}$ channels are also promising targets for new therapies because their blockade could prevent glutamate release.

The following sections highlight certain drugs that target the glutamate system and that have been tested in randomized clinical trials in ALS. Drugs directed at NMDA receptors include riluzole and memantine, while talampanel, riluzole and topiramate target AMPA receptors. These agents also possess other mechanisms of action but their effect on glutamate receptors is likely central to any potential neuroprotective properties in ALS. Riluzole and ceftriaxone also target glutamate transporters. Gabapentin, lamotrigine, topiramate and riluzole have action on voltage gated-Na+ ${ }^{+}$and $\mathrm{Ca}^{2+}$ channels.

\section{ANTI-GLUTAMATERGIC AGENTS IN HUMAN ALS}

\subsection{Riluzole}

\subsubsection{Background}

Riluzole (Fig. 3), a benzothiazole derivative, is the only drug approved for treatment of ALS and could be effective for treatment of other neurodegenerative and neuropsychiatric disorders, although additional research is needed [94-96]. Two positive trials of riluzole showed extension of survival in ALS due to the drug [97].

\subsubsection{Structure-activity Relationship}

Riluzole (2-amino-6-trifluoromethoxybenzothiazole) was initially developed as an anticonvulsant agent and was considered the most efficacious of numerous analogs $[98,99]$. 


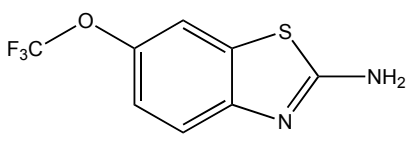

Riluzole
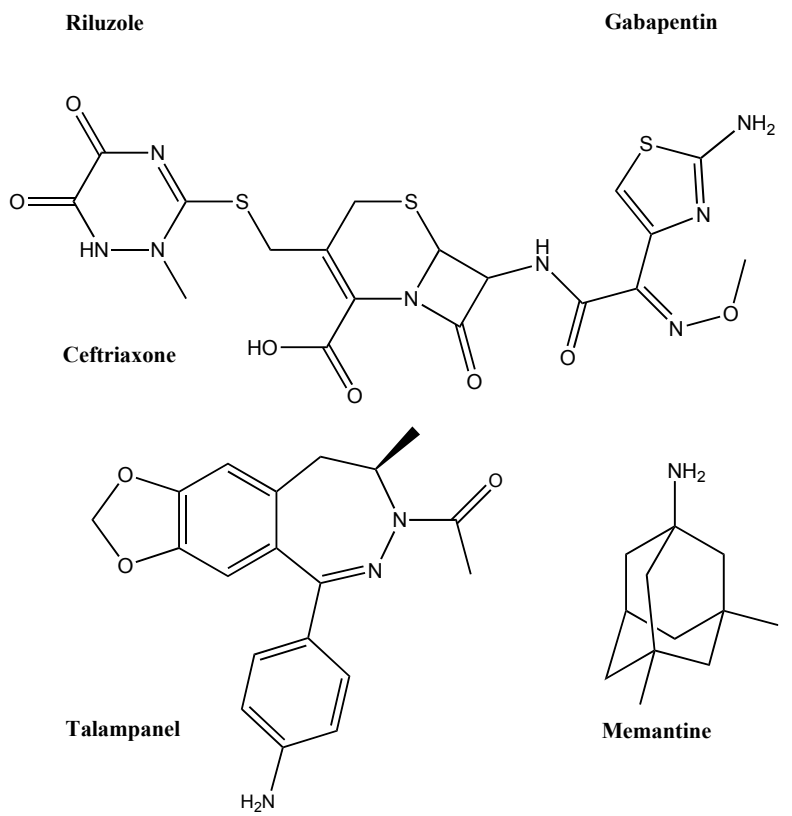

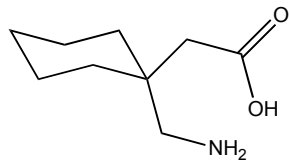

Gabapentin
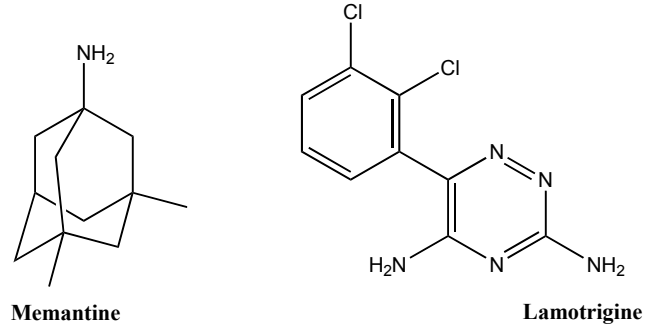

Fig. (3). Chemical structures of anti-glutamatergic medications tested in ALS, including riluzole, the only agent proved neuroprotective for ALS to date.

Riluzole blocks the $\mathrm{Na}^{+}$channel by binding the channel's alpha subunit Nav1.6 [100]. A docking study, which could aid medicinal chemists in the design of new sodium channel protein ligands, uses the virtual alpha subunit (Nav1.6 $\mathrm{Na}^{+}$ channel) [101] through homology modeling of the brain isoform of the human voltage-gated sodium channel (Nav1.2) [102] (PDB: 2KAV Fig. 4). Riluzole appears to interact with the channel's polar glycine residues Tyr 1787 and Leu 1843 ( $\mathrm{NH}_{2}$ function) as well as Gln 1799 (aromatic cycle). Riluzole makes contact at diverse points of the voltage-gated sodium channel protein, including 3 aromatic hydrogens, $\mathrm{NH}$, and aromatic nitrogen.

Riluzole undergoes hepatic metabolism; serum levels vary patient-to-patient due to heterogeneous expression of cytochrome P450 and inconstant first pass elimination [103, 104]. To reduce inter-individual variability, the amino function of the core structure was protected through pharmacomodulation. The design of riluzole prodrugs is an example of how optimization of the ADMET (absorption, distribution, metabolism, excretion, toxicity) proprieties of a drug can be achieved [105]. In one experiment, the exocyclic nitrogen on riluzole was masked by a bulky amide group to prevent its oxidation by the CYP1A2 isoform of cytochrome P450. One prodrug (Fig. 4) was identified as promising after evaluation for in vitro stability [105].

A starting point in the design of new compounds for ALS could be to target two mechanisms with dual derivatives: a neuroprotective riluzole skeleton could be coupled to a neuroprotective GABAergic unit. This approach, using pharmacophore distance mapping of the aromatic cycle, hydrogen bonding domain, and electron donor system, has produced new anticonvulsant molecules [106]. A 3D-QSAR study that required three-dimensional superimposition of molecules in the calculations, used computed potentials to examine the steric fields (shape of the molecule), hydrophobic regions (water-soluble surfaces), and electrostatic fields of compounds. This form of quantitative SAR modeling produces predictive models derived from correlating biological activity with descriptors that represent molecular structure. A 3DQSAR study that evaluated riluzole analogs in the design of new anticonvulsants, found a 1-acetylpyrazolin ring to be a crucial pharmacophoric group for the activity of benzothiazole compounds [107]. This kind of process could also be used to design new agents for ALS.

Some animal studies have found that, due to good lipid solubility and an efficient blood-brain barrier transporter, levels of riluzole are four- to six fold higher than blood levels after oral dosing, and that high levels can persist many hours after a single dose [108-113]. Riluzole is highly lipid soluble, with an octanol:water partition coefficient of 3,000:1 [114] and may enter brain in part by passive diffusion [113].

\subsubsection{Mechanisms of Neuroprotection}

The means through which riluzole influences neurodegeneration in ALS are not fully elucidated. The chief mechanism appears to be via reduction of glutamate levels at the synaptic cleft $[115,116]$. The drug may also exert neuroprotective actions through other processes, including inhibition of glutamate release and non-competitive post-synaptic inhibition of NMDA and AMPA receptors [96, 117].

One explanation for the limited understanding of mechanisms despite a large body of research on the topic is that 


\section{Potential strategies to design new drugs for ALS}

Structure-based drug design:

Docking studies on receptor or transporter implicated in the pathology

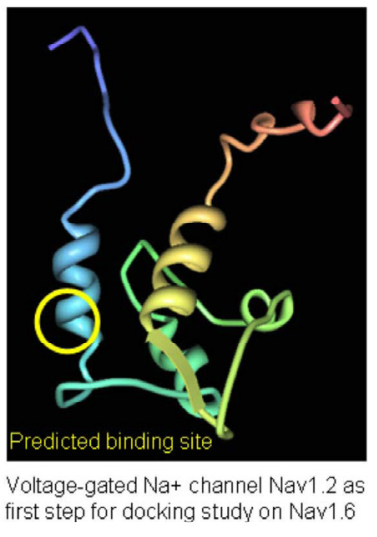

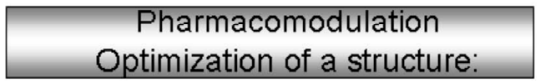

-Better affinity, better selectivity especially for multifunctional drugs targeting

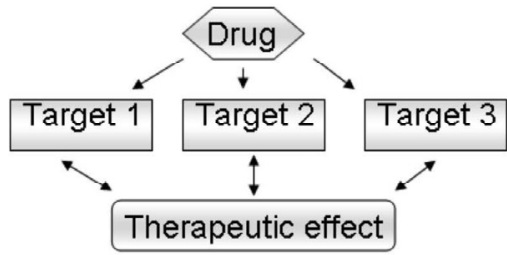

- Better ADMET (administration, distribution, metabolism, excretion, toxicity) properties

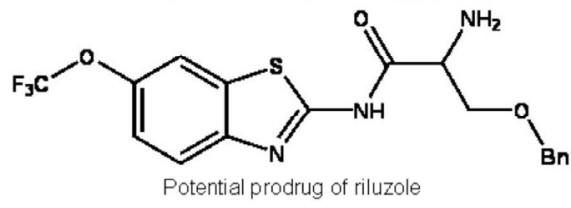

Fig. (4). Potential future strategies for drug development in ALS.

riluzole, at different concentrations, may exert a range of actions [118]. Initially, it was thought that riluzole acted only to reduce glutamatergic synaptic transmission [96, 119-123] (Fig. 1). Other studies described inhibition of the persistent $\mathrm{Na}^{+}$current $[120,124,125]$, reduced action potential firing [124-126], potentiation of the $\mathrm{Ca}^{2+}$-dependent $\mathrm{K}^{+}$current $[127,128]$, and inhibition of voltage-gated $\mathrm{Ca}^{2+}$ channels [120, 129, 130]. Riluzole may also have independent effects, influencing both central and peripheral nerve function as shown by partial normalization of cortical hyperexcitability and a reduction of transient $\mathrm{Na}^{+}$conductances [131].

It can be difficult to distinguish the effects of riluzole on glutamate release from direct actions on glutamate receptors [96]. Numerous studies have examined the influence of riluzole on presynaptic excitability [119, 121, 132-135], finding minor changes in postsynaptic glutamate receptor responses $[119,121]$, or, using spontaneous excitatory postsynaptic currents (EPSC), effects on glutamatergic transmission through both reduced presynaptic release and down regulation of postsynaptic ionotropic glutamate receptors $[122,136]$.

Riluzole increases cell surface expression of the AMPA subunits GluR1 and GluR2, and induces changes in AMPA trafficking [137]. It could also act on NMDA receptors, although the receptor binding site has not yet been described [119]. Riluzole might have indirect actions via a G-proteindependant signalling pathway [138], and has been shown to inhibit a protein kinase C (PKC) [139] that is responsible for regulation of presynaptic NMDA receptors and glutamate release.

Riluzole may stimulate glutamate uptake by both astrocytes and neurons through increased expression and activity of the glutamate transporter GLT-1, without specificity for EAAT1/GLAST, EAAT2/GLT-1 or EAAT3/EAAC1 [39,
140, 141]. Riluzole upregulates GLT-1 levels and activity in cultured primary mouse striatal astrocytes, independent of actions on ion channels [142]. In one study, cultured C6 astroglial cells were used to examine three independent intracellular pathways of glutamate metabolism, confirming that riluzole stimulates glutamate uptake and is an enhancer of EAAT1, dependent on the PKC, fibroblast growth factor receptor (FGFR) and phosphatidylinositol 3-kinase (PI3K) pathways [143]. Riluzole can also activate the transient receptor potential channel C5 (TRPC5), a $\mathrm{Ca}^{2+}$-permeable cation channel that is expressed in brain. The channel helps regulate the morphology and motility of neuronal growth cones and neurite length, as well as the release of neurotransmitters such as $\gamma$-aminobutyric acid (GABA) [144].

The effects of riluzole in ALS could also be partially explained by increased glucose influx in damaged neurons and skeletal muscle tissues [145], and the drug might act as an antioxidant [143, 146, 147], offsetting the usual negative regulation of glutamate uptake in response to oxidative stress [148-150]. Lastly, riluzole could inhibit GABAergic transmission and potentiate function of postsynaptic GABA (A)receptors [151]. Limited data are available from direct studies in motor neurons [143].

\subsubsection{Development for ALS and Current Role in Clinical Care}

As of this writing, riluzole is the only neuroprotective agent approved for ALS and is widely prescribed in clinical practice. While the effect on disease progression is modest, the positive clinical trials helped solidify the theories of excitotoxic cell death in ALS and led to trials of other agents that act on glutamate pathways in ALS and other neurodegenerative diseases. 
Riluzole was approved by regulatory agencies in 1995 following two randomized controlled trials, which showed that the drug extends survival in ALS [97]. In the first trial, which enrolled 155 patients, $74 \%$ in the riluzole group and $58 \%$ in the placebo group were still alive at 12 months of follow-up ( $\mathrm{p}=0.014) ; 49 \%$ in the riluzole group and $37 \%$ in the placebo group were alive at 21 months $(\mathrm{p}=0.046)$. At trial conclusion, median survival was 532 days in the riluzole group and 449 days in the placebo group. Overall, riluzole reduced mortality by $38.6 \%$ at 12 months and $19.4 \%$ at 21 months [97]. The deterioration in muscle strength was also slower in the riluzole group $(\mathrm{p}=0.028)$. The second trial, a dose ranging study in 959 patients, showed the adjusted risk of death in the $100 \mathrm{mg}$ riluzole group was $0.65(\mathrm{p}=0.002)$ compared to placebo after 18 months of follow-up [12]. The effect was not apparent to patients and neither trial showed benefit in quality of life. A meta-analysis of three published trials with 876 riluzole-treated and 406 placebo-treated patients [152] showed that riluzole prolongs survival by approximately $11 \%$, or about 2 months. The long-term safety of riluzole therapy has been shown [153]. The most common side effects are diarrhea, dizziness, fatigue, nausea, and somnolence. Elevation of liver enzymes can occur, but rarely to levels that are clinically meaningful. Dose-adjustment based on serum levels, one approach to optimizing treatment, is seldom done in practice. Most patients in Europe, where the health systems cover the cost, and more than half of patients in the U.S. take the drug. Riluzole is considered just one aspect of ALS care; non-invasive ventilation, multidisciplinary clinics and possibly gastrostomy also make small but important contributions to life expectancy and quality of life [69]. Palliative care and hospice help patients have comfort and dignity in advanced stages.

\subsection{Other Agents Affecting the Glutamate System}

\subsubsection{Gabapentin}

\subsubsection{Background}

Gabapentin (1-(aminomethyl)cyclohexane-acetic acid, Neurontin ${ }^{\circledR}$, Fig. 3) was first shown to be an effective anticonvulsant agent in different animal models of epilepsy [154]. In humans, it prevents partial and generalized tonicclonic seizures when prescribed as monotherapy or with other drugs [155-157]. In animal models, gabapentin appears to block nociceptive responses, producing analgesic effects, and to possess anxiolytic-like activity [158].

\subsubsection{Structure-activity Relationship}

At the GABA 3-position, gabapentin has bulky aliphatic chemical substitutions that alter its pharmacological properties $[159,160]$. This amino acid-like structure has one carboxylic acid terminus and one amino group terminus, and is attached to a cyclohexane. Hybrid peptide and bioconjugate prodrugs of gabapentin have been designed to improve its pharmacokinetic and pharmacological properties [161]. Quantitative Structure Activity Relationship (QSAR) studies have examined the anticonvulsant, but not antiglutamatergic, effects of gabapentin. It is difficult to extrapolate anti-epileptic structure-activity relationships to ALS, especially since the molecular target mediating potential neuroprotective effects is largely unknown. Pregabalin, a gabapentin-derivate, and XP13512, a gabapentin prodrug, were developed to enhance the clinical effects of the parent drug. Pharmacomodulation of gabapentin and pregabalin was done to enhance their pharmacological actions through binding to the $\alpha_{2} \delta$ subunit of a voltage gated calcium channel $[162,163]$. No data are available for ALS.

\subsubsection{Mechanisms of Neuroprotection}

Gabapentin has no effect on GABA receptors and does not modulate GABA receptor function like conventional GABAergic agents. Different experiments point toward various cellular and molecular targets for gabapentin, but a clear consensus has not been reached. Gabapentin binds with high affinity to a binding site associated with the $\alpha 2-\delta$ subunit, an auxiliary subunit, of the voltage-gated $\mathrm{Ca}^{2+}$ channel [164]. The apparent effect on the presynaptic neuron is to inhibit glutamate release at excitatory synapses, reducing excitatory neurotransmission [165]. Gabapentin may also act to reduce the release of some monoamine neurotransmitters [166], and could inhibit voltage-gated sodium channels [167]. Gabapentin appears to have high-affinity for binding sites in brain membranes and is able to cross several lipid membrane barriers via system $\mathrm{L}$ amino acid transporters, where it competes with leucine, isoleucine, valine and phenylalanine. Gabapentin may decrease the rate of formation of glutamate from the branched-chain amino acids leucine, isoleucine, and valine, compensating for abnormal glutamate uptake [168]. The synthesis of glutamate from branched-amino acids involves the transamination of $\alpha$-ketoglutarate by the amino acid aminotransferase (BCAA-T). BCAA-T is competitively inhibited by gabapentin $\left(K_{\mathrm{i}}=0.6-1.2 \mathrm{mM}\right.$ vs $K_{\mathrm{m}}=0.4-1.2 \mathrm{mM}$, for substrate affinity) [169], with selectivity for the isoform present in brain cytosol [170]. In combination, in vitro studies suggest that one action of the drug could be to decrease of levels of cytosolic glutamate. In vitro studies have also shown that gabapentin could enhance the activity of glutamate dehydrogenase (GDH) [169], which converts glutamate to $\alpha$-ketoglutarate. Numerous electrophysiological studies have shown an interaction between gabapentin and NMDA responses in cortical neurons, in the absence of exogeneous glycine. Gabapentin prevents motor neuron degeneration in an in vitro model of ALS [171] and delays death in the ALS transgenic animal model [172].

\subsubsection{Development for $A L S$}

Gabapentin has been studied extensively in people with ALS. One analysis of $\mathrm{N}$-acetylaspartate/creatine (NAA/Cr) ratios by magnetic resonance spectroscopy found no beneficial effect of the drug on neuronal integrity in motor or nonmotor cerebral regions [173].

The first clinical trial of gabapentin was conducted in 1996 [174]. This phase II double-blind placebo-controlled trial randomly assigned 147 ALS patients to $2400 \mathrm{mg} / \mathrm{d}$ or placebo for six months. The primary endpoint, which was assessed every four weeks, measured quantitative arm muscle strength. Results of this study showed a non-significant trend of approximately $37 \%$ slower deterioration in treated compared to control patients. Quantitative strength was assessed by an apparatus known as the TQNE, which gives reproducible results, but can be increasingly difficult for patients to undergo as the disease advances. As a conse- 
quence, the results were biased by a high number of patients who withdrew from the study $(\mathrm{n}=44$, around $30 \%)$. Patients were also older in the gabapentin than placebo group [174]. Even so, the results were considered promising enough to design a phase III trial that assessed 1) a higher dosage (3600 $\mathrm{mg} v s 2400 \mathrm{mg}$ ) of gabapentin, 2) for a longer period of follow-up (9 months vs 6 months) and 3) in a larger sample (204 ALS patients vs 147) [175]. The phase III trial used the same primary endpoint, quantitative strength, as the phase II study. One hundred twenty-eight of 204 patients completed the study (65 in the gabapentin group). Baseline features were again imbalanced between groups, with significantly shorter disease duration in the gabapentin group (438 vs 548 days). At study conclusion, there was no difference in the rate of decline in strength or any predefined secondary endpoints. When the phase II and phase III data were combined, giving greater power to the analyses, the rate of deterioration was greater in treated than placebo patients, suggesting a potential toxic effect of gabapentin at high dosages. This trial, which ushered in an era of increasingly sophisticated clinical study design in ALS, raised questions that continue to befuddle ALS trialists today: How to reduce patient dropout in a disease as rapidly progressive as ALS, how to ensure that phase II trials produce meaningful results, and how to identify the correct dose for neuroprotection in humans [176]. Excess dropout and missing data hinder a trial in two ways: They reduce power, which depends in part on sample size, to detect a predefined effect size due to the medication and they bias results if dropout occurs in one group more than another. In a disease as resistant to discovery as ALS has proved to be, even if a medication possesses neuroprotective properties, a trial might be negative if there is any flaw in design or conduct, and precisely the correct dose is not tested. In retrospect, the trend toward improvement in the phase II trial was probably due to statistical chance rather than true benefit of the drug.

\subsubsection{Topiramate}

\subsubsection{Background}

Topiramate (Fig. 3) is a sulfamate substituted monosaccharide. Approved by regulatory agencies in 2012 for epilepsy [177], topiramate is now also indicated in the treatment of migraine headache. The drug is effective against partial epilepsy in adults and Lennox-Gastaut syndrome in children [178]. Topiramate might be effective for tremor [179-181] and treatment-resistant schizophrenia [182]. It has been tested in other neurological and psychiatric conditions such as anxiety, bipolar disorder, and neuropathic pain [183-186].

\subsubsection{Structure-activity Relationship}

Topiramate is a tetrahydropyrane with one sulphonamide attached where the hydroxyls are protected by two methylethylidene groups. Topiramate is an analog of fructose-1,6diphosphate, which may inhibit fructose 1,6-bisphosphatase, an enzyme that converts fructose-1,6-bisphosphate to fructose 6-phosphate. The structure of topiramate suggests that it could impact different targets, including receptors, ion channels and enzymes. Related compounds such as talampanel are quite different chemically but bind to a common target protein, the AMPA receptor. Analogs of bis-O-(1methylethylidene)- $\beta$-D-fructopyranose have been synthe- sized and appear to inhibit seven human isoforms of the zinc enzyme carbonic anhydrase (hCA, EC 4.2.1.1) [187, 188]. Other carbonic anhydrase inhibitors are also used as anticonvulsants in the treatment of epilepsy [189]. Two of the new compounds showed better anticonvulsant activity in mice than Topiramate. A structure activity study reported that a sugar sulfamate cyclic sulfate (RWJ-37947) had promising anticonvulsant activity, but no further results have been published on this compound [190]. These molecules are heterogeneous, with distinct functional groups, so it is likely that the entire molecule does not produce the pharmacological effect. Current research is focused on deriving analogues of topiramate; carbonic anhydrase inhibitors have been singled out because of their beneficial effect on epilepsy [187, 188, 191].

\subsubsection{Mechanism of Neuroprotection}

Topiramate has different pharmacological properties that could contribute to a neuroprotective effect [32, 192-197], including $1^{\circ}$ ) negative modulation of voltage-gated $\mathrm{Na}^{+}$ channels [198-201]; $2^{\circ}$ ) negative modulation of L-type high voltage-activated $\mathrm{Ca}^{2+}$ channels [202]; and $3^{\circ}$ ) antagonism of the AMPA and kainate glutamate receptors [203, 204].

The neuroprotective role of topiramate on Glu-induced excitotoxicity may be best explained by interference with kainate receptors [205]. The anti-kainate actions of topiramate appear to be mediated through antagonism of kainateactivated cobalt (Co2p) flux [204]. This selective antagonism limits toxicity induced by prolonged glutamatergic stimulation of NMDA receptors [206, 207], and is associated with alterations in the phosphorylation state of the kainate receptor $[177,198,203,208]$.

In astrocytes, inhibition of AMPA-induced $\mathrm{Ca}^{2}$ accumulation is inversely related to the level of protein kinase Amediated phosphorylation of channels that are normally activated by AMPA [205]. Topiramate only binds to AMPA receptors when dephosphorylated, suggesting an allosteric modulatory effect of topiramate on the ion channel. Activation of AMPA receptors blocks the inwardly rectifying $\mathrm{K}^{+}$ channels by a mechanism coupled to AMPA receptormediated $\mathrm{Na}^{+}$influx [209]. Topiramate could also reduce the phosphorylation level of GluR1 subunits.

Direct modulation of $\mathrm{Ca}^{2+}$ permeability by topiramate at AMPA/kainate receptors appears unlikely [210]. Topiramate probably reduces depolarization-evoked $\mathrm{Ca}^{2+}$ influx by processes other than a direct effect on voltage-dependent $\mathrm{Ca}^{2+}$ channels. Postsynaptic influences could reduce somatic or dendritic AMPA and kainate receptor-induced membrane depolarization.

Topiramate may also enhance some types of GABAA receptors [211, 212] and $\mathrm{K}^{+}$channel currents [213], as well as inhibit all carbonic anhydrase isoforms in blood and brain (with $K_{\mathrm{i}} \mathrm{s}$ in the nanomolar range) [214]. Topiramate prevented loss of motor neurons in one in vitro model of excitotoxicity, but had no effect in an animal model of ALS [215].

\subsubsection{Development for $A L S$}

A single clinical trial testing the efficacy of topiramate was carried out in people with ALS. The results of the laboratory and mouse model experiments were published concur- 
rently [215]. A phase III randomized placebo-controlled trial examined the effect of up to $800 \mathrm{mg} / \mathrm{d}$ on quantitative arm strength in 296 patients who were followed for 12 months [216]. Baseline demographic and phenotypic features were balanced between groups. At the end of the trial, arm strength deteriorated more rapidly in patients randomized to topiramate compared to placebo (-0.0997vs $-0.0748, t$-test, $p$ value $=0.012)$, as did grip strength $(-0.111 v s-0.084$, $t$-test, $p=0.017$ ). There were no differences between groups in secondary endpoints, including the ALS Functional Rating Scale (ALSFRS), breathing capacity or time to death. The more rapid deterioration of the primary outcome measure in treated patients was thought to be due, in part, to side effects of the drug. The decline in strength was paralleled by a 2.5 fold greater loss of weight in the topiramate group $(-0.93 \mathrm{vs}-$ $0.37 \mathrm{~kg} / \mathrm{months}, p<0.0001)$. Weight loss is an independent negative prognostic indicator in ALS [217].

The dose for the trial was selected to achieve blood concentrations of $45 \mu \mathrm{mol} / \mathrm{L}$, a value in the therapeutic range for epilepsy. While the approach is logical, one conclusion, in hindsight, from the trial is that dose cannot be extrapolated from other diseases; a drug that is effective in one disease and at a certain dose, might not be effective in ALS or the dose may be different. In retrospect, the phase III efficacy trial was done with inadequate dose exploration in preliminary trials, which could have better determined the adverse event profile in patients with ALS as well as the dose most likely to have a neuroprotective effect. A recurrent obstacle facing ALS trialists is how best to select a dose for ALS in phase I and II trials that are too small examine efficacy and in a disease with no clear biological markers. Non-traditional phase II designs that choose dose rather than measure absolute efficacy are being tried [176].

\subsubsection{Ceftriaxone}

\subsubsection{Background}

Ceftriaxone (Fig. 3), a $\beta$-lactam antibiotic, is a thirdgeneration cephalosporin that inhibits bacterial cell wall synthesis by binding to penicillin-binding proteins. Ceftriaxone is neuroprotective in in vitro [42] and in vivo models of different neurologic diseases, including spinal muscular atrophy [218], Huntington's disease [219], ischemia [220-222] and multiple sclerosis [223].

\subsubsection{Structure-activity Relationship}

QSAR studies show that ceftriaxone has moderate lipophilicity $(\log \mathrm{P}=1.6-1.8)$ and diffuses well into CSF [224]. Ceftriaxone mediates EAAT2 protein induction by interacting with the nuclear factor NF- $\kappa B$ [225]. A screening study of various antibiotic compounds identified 15 different $\beta$ lactam antibiotics that were able to stimulate EAAT2 protein expression by more than two-fold [42]. Since that study, no new antibiotics have been found to be as powerful enhancers of EAAT2, although molecular modeling with docking studies could search for new drugs that bind to this same site [226]. Despite differences in chemical structure, ampicillin and penicillin also induce EAAT2 expression at the translational level [227]. To date, the characteristics of the ceftriaxone structure that mediate its effect on EAAT2 are not clearly defined.

\subsubsection{Mechanism of Neuroprotection}

Ceftriaxone is a transcriptional activator of EAAT2 expression, facilitating glutamate uptake by astroglial cells [42, $225,228,229]$. The $\mathrm{EC}_{50}$ for increasing EAAT2 expression is $3.5 \mu \mathrm{M}$, similar to CSF levels obtained with therapy for meningitis. The mechanism of enhanced EAAT2 gene expression is unclear.

Ceftriaxone is neuroprotective in in vitro in models of stroke and motor neuron degeneration, and increases the biochemical and functional activity of the transporter in vivo [42]. Ceftriaxone exerts neuroprotective effects in culture models of excitotoxicity [171, 230], and has antioxidant activity [231, 232]. The benefit of ceftriaxone in ALS models could involve $\mathrm{Cu}(\mathrm{II})$-attenuation [233].

$\mathrm{NF}-\kappa \mathrm{B}$, a transcription factor that regulates the expression of numerous genes and is involved in immune responses, as well as cell growth, survival, and differentiation $[234,235]$, appears to attenuate the ceftriaxone-mediated induction of EAAT2. The promoter for EAAT2 has four NF$\kappa \mathrm{B}$ binding sites, which regulate EAAT2 expression [236238]. The EAAT2 promoter could itself be regulated by extracellular signals and NF- $\kappa \mathrm{B}$ through different signalling pathways in combination with other transcription factors $(\mathrm{N}-$ Myc) [237]. Ceftriaxone could modulate the glutamate transporter through NF- $\kappa \mathrm{B}$-mediated EAAT2 transcriptional activation [239]. Of $\beta$-lactam antibiotics identified in the high throughput screen assessing potential neuroprotective activity in ALS [42], ceftriaxone was selected for human studies because of its good CNS penetration and longer halflife than other agents in its class [240]. In the murine model of ALS, ceftriaxone delayed loss of neurons and increased muscle strength, as well as survival [42].

\subsubsection{Development for ALS}

Following the encouraging results in the laboratory, including the positive study in the murine model, a human clinical trial was designed that incorporated all three trial phases into a single continuous trial. This design would, ideally, improve efficiency by including the same patients and reducing down time among phases, while, at the same time, achieving important goals of all three phases. Sixty-six patients were enrolled in the phase I (pharmacokinetics) and phase II (safety and tolerability) stages [241]. Ceftriaxone levels were assessed seven days after initiation of the protocol to determine the dosage $(2 \mathrm{~g} / \mathrm{d}$ or $4 \mathrm{~g} / \mathrm{d})$ that provided a CSF trough concentration of at least $1 \mathrm{mM}$ in at least $80 \%$ of the cohort. Both doses achieved this threshold but the high dose had the advantage allowing longer drug holidays (3 days instead of 2 days).

The phase II stage examined three arms (placebo, ceftriaxone $2 \mathrm{~g} / \mathrm{d}$, ceftriaxone $4 \mathrm{~g} / \mathrm{d}$ ), and showed that both dosages were reasonably safe and well tolerated. Abdominal pain and cholelithiasis occurred, in a dose-dependent fashion, more frequently in patients who received ceftriaxone ( $p$ $=0.02$ and $p=0.0001$ respectively), but both dosage levels met predefined criteria for tolerability in stages 1 and 2 .

A data and safety monitoring board reviewed pharmacokinetic, safety and tolerability data and recommended continuing to stage 3 with the high dosage ceftriaxone $(4 \mathrm{~g} /$ day 
divided twice daily). The phase III trial was stopped when an interim analysis determined that a positive outcome, as measured by survival and rate of progression in function, was unlikely to be achieved.

This trial did better than its predecessors in accomplishing important goals of drug development. There was good scientific justification for testing the drug; phase I determined pharmacokinetic profiles and confirmed entry into the brain; phase II assessed the safety of two different doses; and phase III had good power to detect a meaningful effect. It was ten years from the time $\beta$-lactam antibiotics were identified in the high throughput screen to completion of this multimillion dollar trial. Planned enrollment in phase III was 513 patients at 58 centers. Considerable financial and intellectual investment was made by the U.S. National Institutes of Health and Food and Drug Administration. The vast resources contributed to this trial that was stopped early due to inefficacy exemplifies the obstacles facing researchers, the great need for better understanding of causes, identification of biomarkers as well as development of drugs that target disease physiology in more sophisticated ways.

\subsubsection{Talampanel}

\subsubsection{Background}

Talampanel (LY300164; GYKI 53773, Fig. 3) was one of the first active AMPA receptor antagonists studied in humans. The drug was tested in trials of epilepsy, with efficacy for seizures taken as evidence of bioavailability within the CNS [242, 243]. Talampanel appears to potentiate the anticonvulsant activity of valproate, carbamazepine, diphenylhydantoin and phenobarbital [244], increasing the potency of valproate, diazepam, clonazepam [245] for seizures, and enhancing the protective action of valproate and ethosuximide in pentylenetetrazol-induced experimental convulsions in the laboratory.

\subsubsection{Structure-activity Relationship}

Talampanel is an imidazo-benzodiazepine: (8R)-7-acetyl5-(4-aminophenyl)-8,9-dihydro-8-methyl-7H-1,3-dioxolo [4,5-h][2,3]benzodiazepine (GYKI 53733/ LY300164) [246]. It is a small molecule with good blood-brain-barrier penetration.

The 2,3-benzodiazepine family has been used to describe the pharmacophores that are recognized by AMPA receptors [163, 247-249]. Hundreds of 3- $N$-substituted-3,4-dihydro2,3-benzodiazepine analogues have been developed using talampanel as the lead structure, and some have demonstrated good in vitro AMPA receptor affinity with in vivo efficacy as anti-epileptic drugs [250, 251]. The importance of stereoselectivity in AMPA receptor recognition is highlighted by the higher activity of R-enantiomers such as ()talampanel. On the diazine cycle, the C-4 bearing the chiral methyl group is an important determinant of affinity. If it is replaced by a carbonyl group, this analog binds to another site on the AMPA receptor [252]. To produce noncompetitive affinity for the receptor, the C-4 methyl group must be fixed on a 2,3-benzodiazepine skeleton associated with a 7,8methylenedioxy group [253]. Different functional groups introduced to the 2,3-benzodiazepine system produce different affinities for the AMPA receptor [249]. QSAR studies indicate that anticonvulsant activity can be maximized through manipulation of the HOMO (highest occupied molecular orbital) energy, the lipophilicity, and the number of nitrogen atoms; and that a higher number of donor hydrogen bonds can have an unfavorable effect [254]. Talampanel and its $(+)$ counterpart have been used to evaluate the mechanism of inhibition and selectivity for the four AMPA receptor subunits GluA1-4; three different noncompetitive sites on the GluA2Q AMPA receptor have been described as important for the interaction [255], but the location of these negative allosteric ligand binding sites on the AMPA receptor is not yet known. The best fit from a three-dimensional pharmacophore model indicated that two hydrophobic groups, one hydrogen-bond acceptor and one aromatic region are important for non-competitive antagonist activity at the AMPA receptor [247, 256]. A separate study identified two donor sites, one donor atom and a hydrophobic center [257], but the results need confirmation by 3D QSAR study.

The affinity of talampanel for the receptor can be enhanced through allosteric modulation of recombinant AMPA receptors by hetero-oligomerization with GluR2 [258]. In a 2006 study, ZK 187638, a talampanel analog [259] and noncompetitive AMPA antagonist, was shown to improve motor neuron function in mSOD1G93A transgenic mice [260]. In parallel, perampanel [2-(2-oxo-1-phenyl-5-pyridin-2-yl-1,2dihydropyridin-3-yl)benzonitrile] [261-263] was identified from diverse pharmacomodulation studies as a potential scaffold for the development of new AMPA receptor ligands. Both agents could be developed further for ALS. Other molecules may be more potent than talampanel [264, 265], but to date, none have been evaluated in ALS.

The crystalline structure of the AMPA-sensitive, homotetrameric, rat GluA2 receptor in complex with a competitive antagonist has also been described (PDB: 3KG2) [266]. To facilitate the design of novel AMPA receptor antagonists, a modified model of the AMPA receptor binding site that includes key residues involved in ligand recognition (PDB: 1N0T) was created [267]. Other antagonists that bind AMPA receptors have been co-crystallized (PDB: 3B7D) [268] and PDB: 1FTL, 1FTJ) [269] and used in the design of new noncompetitive glutamate receptor antagonists [270, 271]. Docking studies to design new ligands for use in ALS could be done based on these data.

\subsubsection{Mechanism of Neuroprotection}

Noncompetitive AMPA antagonists, like talampanel [272, 273], protect motor neurons from excitotoxicity [274], appear to be effective in models of neurological disease irrespective of glutamate levels or polarization state of the synaptic membrane [275, 276], and leave normal glutamatergic activity unaffected after prolonged use. In addition to binding AMPA receptors, talampanel may also have antiinflammatory properties in the CNS and attenuate caspase- 3 induced proapoptotic pathways [277]. AMPA antagonists prolong survival in the transgenic G93A mouse model [278, 279].

\subsubsection{Development for $A L S$}

A preliminary trial of talampanel in ALS ended without appreciable clinical benefit [280]. This phase II placebocontrolled trial randomized 59 patients in a $2 / 1 \mathrm{drug} /$ placebo 
ratio. The dosage was titrated as tolerated from $20 \mathrm{mg}$ to 50 $\mathrm{mg}$ three times daily in weekly increments of $30 \mathrm{mg} /$ day. Efficacy was assessed by quantitative muscle strength, pulmonary function, the ALS Functional Rating Scale, and survival. There were no differences in demographic data between groups, and $85 \%$ of patients reached the maximal daily dosage. Dizziness, reported by $60 \%$ of patients enrolled in the treatment group, was a common adverse effect. Functional scores (30\%) and muscle strength (15\%) declined more slowly, trends that did not reach statistical significance, in treated compared to placebo patients. Change in respiratory strength was similar between groups. Although not significant, the results were hopeful enough that a second 52 week phase II multicenter placebo-controlled, trial was designed to assess the efficacy, tolerance and safety of two dosages of talampanel ( $25 \mathrm{mg}$ and $50 \mathrm{mg}$ three times daily) compared to placebo. When the trial ended in May 2010, Teva Pharmaceuticals, the sponsor of the trial, announced a negative outcome, but the results have not been published or posted on clinical trial registry websites. Investigators and pharmaceutical companies have a responsibility to publish trial results, positive or negative, in a timely way, so that other investigators can examine data and make decisions regarding how best to pursue new avenues for ALS in their own research.

\subsubsection{Memantine}

\subsubsection{Background}

Memantine (Fig. 3) was first synthesized as a $N$ arylsulfonyl- $N$-3,5-dimethyladamantylurea derivative to reduce hyperglycemia [281]. The drug was initially registered in Germany for indications related to neurological diseases in 1978 [282], but an effect on NMDA receptors was not described until many years later [283-287]. Efficacy has now been shown in randomized controlled trials in a variety of dementias [288]. Memantine might also have beneficial effects in other disorders, including Parkinson disease, stroke, epilepsy, trauma, drug dependence and chronic pain [289293], but additional research is needed.

\subsubsection{Structure-activity Relationship}

Memantine (1-amino-3,5-dimethyl-adamantane) is derived from amantadine and belongs to the aminoadamantane class of organic molecules. The drug exhibits excellent CNS penetration [294]. CSF levels of memantine correlate with serum values (ratio serum/CSF at $0.52+/-0.094$ ), and free levels are estimated to be similar in both fluids. Even though $\mathrm{CSF}$ concentrations are lower than the $\mathrm{IC}_{50}$ for NMDA receptors, memantine appears to bind its target on the receptor, likely because of adequate free levels [294]. Memantine blocks open NMDA channels through non-competitive antagonism [295]. Key binding interactions have been examined and compared to amantadine using the GluN1/GluN2B NMDA receptor on crystalized chimaera Kv1.2 potassium channels (PDB: 2R9R) [296]. Mutations in residues on the third transmembrane (TM3) as well as post-TM3 regions of GluN1 were found to have considerable impact on the memantine $\mathrm{IC}_{50}$ [297]. Hydrophobic interactions between two methyl groups and the binding pocket formed by the residues A645 and A644 on the third transmembrane helices of GluN1 and GluN2B, respectively, have been identified. The addition of methyl groups to amantadine, forming memantine improved affinity of the compound for the receptor [298]. Memantine analogues have been evaluated for their NMDA receptor PCP binding site affinities and compared to MK-801 (dizocilpine), an anticonvulsant drug and potent NMDA receptor antagonist $[299,300]$ that binds selectively and with high affinity to NMDA receptors in the open state [301]. The selectivity of MK-801 is such that it does not influence the binding of ligands on numerous other CNS receptors [282]. A gabapentin-adamantine dual compound was also designed by coupling gabapentin to a memantine ana$\log$, a strategy that could be applied to drug development for ALS [302].

Memantine is an inefficient antagonist of the NMDA receptor, but it could be a starting point for the design of new compounds using docking experiments on the NR2B subunit [298]. The NR2A-glutamate complex defines determinants of glutamate-NMDA recognition; crystal structures of the NR2A ligand-binding core in tetrameric NMDA receptors (PDB: 2A5S) could be employed to design new agents [303]. Docking studies would be especially helpful in the identification of new ligands for NMDA receptors.

\subsubsection{Mechanism of Neuroprotection}

The principle effect of memantine on reducing neuronal loss occurs through correction of excitation-inhibition imbalance [290, 291, 295, 304, 305] at the level of the NMDA receptor [290, 291, 304, 305], but the compound has numerous targets.

Memantine blocks the NMDA receptor in a mechanism similar to that of $\mathrm{Mg}^{2+}$, but with higher affinity and less voltage dependency [306]. The primary binding sites for the two compounds overlap [297, 307-309]. Memantine also binds to a region of the channel pore near but more superficial to agents with psychotomimetic effects such as ketamine and phencyclidine [310]. Because memantine, a noncompetitive antagonist of the receptor, binds to the receptor channel rather than the extracellular glutamate binding site [311], it can rapidly attach and dissociate from the receptor. Memantine appears to detach from NMDA receptors upon strong post-synaptic depolarization but continues to block the channel pore in the setting of moderate prolonged depolarization, preserving normal synaptic activity while inhibiting excitotoxicity [282]. Memantine leaves synaptic activity unaffected by interacting with extra-synaptic NMDA receptors [312] or by blocking receptor activity only in the setting of persistently high levels of glutamate, with no response to the brief spikes that occur in normal synaptic transmission [313, 314]. In therapeutic concentrations, memantine acts on NR1/2C and NR1/2D but not NR1/2A or NR1/2B-containing NMDA receptors [315]. Actions of memantine depend on voltage; the $\mathrm{IC}_{50}$ increases with depolarization $[295,304,305]$. Memantine also blocks type 3 serotonin (5-HT3) and nicotinic acetylcholine receptors (nAChR) with low IC50 [316]. The therapeutic effect of memantine may be enhanced by inhibition of $\alpha-7$ nAChRs (Nicotinic acetylcholine receptors) [317], which are involved in amyloid- $\beta$-induced internalization of receptors [318].

Memantine can also be considered an L-type $\mathrm{Ca}^{2+}$ channel antagonist and might impede activation of voltage acti- 
vated $\mathrm{Na}^{+}$channels, but with potencies that are too weak to produce therapeutically meaningful responses.

Memantine appears to inhibit and reverse hyperphosphorylation of tau that leads to aggregation and sequestration of cytoskeletal proteins, including the microtubuleassociated proteins seen in ALS [319-323]. Memantine increases phosphoinositide turnover with an $\mathrm{EC}_{50}$ of $4.1 \mathrm{mM}$ [324]. Memantine also potentiates inhibitory glycine receptors in spinal cord culture [325].

Preclinical experiments suggest that treatment with memantine could be neuroprotective, reducing excitotoxicity and delaying progression in models of neurodegenerative diseases [326, 327]. Treatment with memantine delayed motor deterioration and extended life span in mSOD1(G93A) ALS mice [328]. When administered after symptom onset, which may better represent how the drug can be given to people, memantine extended survival in the murine model [329], but had no effect on measures of motor function.

\subsubsection{Development for ALS}

Following the positive outcomes in controlled trials and subsequent approval for Alzheimer disease, as well as encouraging reports from the mSOD1 mouse model, two clinical trials were conducted in ALS. The first was a 12-month single-center randomized, double-blinded, placebocontrolled trial that enrolled 63 patients with ALS using standard inclusion criteria. The effect of $20 \mathrm{mg} /$ day doses on the decline in the ALS Functional Rating Scale was assessed at trial conclusion. Overall, memantine was safe and well tolerated. No therapeutic effect on motor function emerged in this small trial, but larger studies are needed [330]. In the second trial, designed to examine safety and changes in CSF biomarkers, 20 patients received $10 \mathrm{mg}$ twice daily for 18 months [323]. Changes in CSF tau were seen in response to the medication and memantine was again well tolerated. These preliminary studies suggest that the drug could be developed further for ALS, with focus on dose selection and development of biomarkers.

\subsubsection{Lamotrigine}

\subsubsection{Background}

Lamotrigine (Fig. 3) is approved in the U.S. as adjunctive therapy for primary generalized and partial epilepsy. The drug also acts as a mood stabilizer, and is indicated for maintenance therapy in bipolar disorder with depression as a prominent feature. Lamotrigine may be effective for acute depression whether or not it is related to bipolar disorder, but additional studies are awaited [331-333].

\subsubsection{Structure-activity Relationship}

Lamotrigine contains a triazine ring that is connected to another aromatic ring, forming an arene-oxide intermediate [334]. It is this intermediate that appears to underlie the skin reactions due to lamotrigine, a meaningful side effect that occurs in $2-7 \%$ of people who take the drug and that ranges from mild to life threatening [335]. The anticonvulsant agents, phenytoin, carbamazepine, and lamotrigine have distinct chemical structures but similar mechanisms of action, all binding to a common site on neuronal $\mathrm{Na}^{+}$channels [336]. The synthesis and in vitro evaluation of new 2,4- diamino-1,3,5-triazine derived neuronal voltage-gated sodium channel blockers can be done on a lamotrigine and phenytoin pharmacophore-based scaffold [337]. Triazine analogues have also been synthesized and evaluated using similar methodology; a 2D pharmacophore that contains at least one aryl unit, one or two electron donor atoms, and a hydrogen bond acceptor/donor unit can examine anticonvulsant activity [338]. A homology study of all four domains was accomplished using the open MthK channel X-Ray structure (PDB: 1lnq) [339]; lamotrigine-binding residues were identified at the center of the pore, near the S6 helices of domains III and IV [340]. Lamotrigine appears to interact with Leu-1465 on the voltage-gated $\mathrm{Na}^{+}$channel, where it binds to the interface between DIV-S6 and DIII-S6 [341]. The channel has low affinity for the drug at resting state $\left(K_{\mathrm{d}}\right.$ $=641 \mu \mathrm{M})$ [342].

\subsubsection{Mechanism of Neuroprotection}

Lamotrigine, initially developed for its antifolate properties [343], inhibits voltage-sensitive $\mathrm{Na}^{+}$channels, as well as the release of glutamate and aspartate [344-348]. Lamotrigine also diminishes neuronal transmission via blockade of $\mathrm{N}$-type calcium-channels and potassium efflux [349, 350]. In high concentrations, lamotrigine inhibits $15-26 \%$ of AMPAevoked depolarization [351].

Lamotrigine also reduces glutamate release in dentate gyrus granule cells through suppression of postsynaptic AMPA receptors [352]. In the laboratory, lamotrigine reduces motor neuron loss to the same degree as the NMDA receptor agonist $\mathrm{MK}-801$ [353, 354]. While lamotrigine is believed to inhibit glutamate release, the changes cannot be detected in CSF of patients with epilepsy [354, 355].

\subsubsection{Development for $A L S$}

The efficacy and tolerability of $300 \mathrm{mg} /$ day of lamotrigine were studied in a double-blind, 6-month placebocontrolled crossover trial in 30 patients with ALS; none took riluzole. The design included a 6 -week period of dose escalation, followed by 16 weeks of treatment, then a 6 week wash-out period before initiating the opposite treatment (placebo or lamotrigine) [354]. CSF levels of excitatory amino acids and lamotrigine were assessed, along with clinical function. There were no differences in any assessment at the conclusion of this small pilot trial.

\section{FUTURE DIRECTIONS}

As the field of medicinal chemistry enters a new era of sophistication, designer drugs optimized for specific cellular events are rapidly moving from theory to reality. In ALS, excitotoxic cell death is a mechanism that might be amendable to targeted drug design but additional work is needed before ideal models that fully recapitulate the complex biochemical events in ALS are realized.

Structural analysis of riluzole, ceftriaxone and dexpramipexole shows that the three chemicals possess the same 5-(2-heteroethyl)thiazol-2-amine group. The structure activity-relationship (SAR) is much more difficult to elucidate, however and few quantitative SAR studies have been reported for ALS, one explanation for the failure of drug development to, so far, translate into meaningful neuroprotec- 
tive therapies. An important next step is to better define how various chemicals interact with disease mechanisms using QSAR.

The development of compounds that act as transcriptional activators of EAAT2 is an especially promising future approach. A series of new compounds that increase EAAT2 protein expression has been described, and further investigation should examine potential therapeutic effects in ALS.

Transplantation of stem cells that secrete gene products or metabolic or neurotrophic factors is another approach to therapy [356]. Genetically reprogrammed stem cells that selectively increase glutamate uptake is one avenue that is worthy of additional research [357].

The hypothesis of glutamate-induced excitotoxicity appears central to events surrounding motor neuron cell death, but other pathophysiological events have also been described, including aggregation of misfolded protein, oxidative stress, and mitochondrial dysfunction. How these processes interact awaits full elucidation, but development of rational "multi-targeted drugs", while far from simple, is a strategy to drug design that also needs exploration [358]. ALS likely has heterogeneous causes, making the problem of finding a single ideal target in a single metabolic pathway overwhelmingly difficult. Similarly, the notion of finding a single diagnostic biomarker or measure of disease progression seems, for the moment, a distant hope. In a clinical trial, some patients might respond to one targeted mechanism while others might not because the diseases may be different or in different stages. Drugs that target multiple targets could treat more mechanisms in ALS; this approach is now possible, but would require extensive preclinical experimentation to define effects before testing in humans.

To date, clinical trials of anti-excitotoxic agents have used drugs that have not been optimized. Negative trial results could mask good results in individual patients or groups of patients. Continued characterization of patients, perhaps using new technologies such as neuroimaging and metabolomics could help identify like groups of patients [359, 360]. A better approach to ALS therapy requires a better understanding of interactions between risk factors, pathophysiological mechanisms, biomarkers and phenotypic characteristics of patients. Personalized medicine in which treatments target individual patients' disease patterns is a future, albeit still remote, goal.

\section{CONCLUSIONS}

ALS, like other age-related degenerative disorders, still has few known causes or meaningful treatments. The course is progressive and death occurs for most patients within several years of onset. Care is now multidisciplinary and includes respiratory support, supplemental feeding and riluzole, all of which prolong survival modestly. Symptomatic medications can be tried but have not been shown to improve survival. Hospice and comfort measures ensure dignity in advanced stages.

Some of the cellular events that occur after disease onset are partially understood, but little is known about how underlying risk factors might take effect or interact. Triggers may act in distant youth or even before birth. It is likely that bet- ter treatments and preventative measures will be identified after the etiologies of ALS are found. In the meantime, medicinal chemistry can make important contributions to the last frontier of medical science, neurodegenerative brain diseases. Better models and better understanding of disease mechanisms, drug development optimized for specific targets such as EAAT-2, definition of structure-activity relationships prior to human testing, design of agents that target multiple targets, and elaboration of disease biomarkers could produce the breakthrough that has eluded five generations of researchers; a leap forward that would not only help relieve the suffering of millions of people, but that would forever change how we perceive aging and, by extension, life.

\section{CONFLICT OF INTEREST}

The author(s) confirm that this article content has no conflicts of interest.

\section{ACKNOWLEDGEMENTS}

Declared none.

\section{ABBREVIATIONS}

ADMET $=$ Absorption, distribution, metabolism, excretion, toxicity

AMPA $=\alpha$-amino-3-hydroxy-5-methyl-4-isoxazole propionic acid

BCAA-T $=$ Amino acid aminotransferase

CSF $\quad=$ Cerebrospinal fluid

CNS $=$ Central Nervous System

DAAO $=$ D-amino acid oxidase

EPSC $=$ Spontaneous excitatory postsynaptic currents

FDA $=$ Food and Drug Administration

EAAT $=$ Excitatory amino acid transporter

$\mathrm{EC}_{50}=$ Half maximal effective concentration

$\mathrm{ED}_{50}=$ Median effective dose

ELISA $=$ Enzyme-linked immunosorbent assay

FGFR $=$ Fibroblast growth factor receptor

GABA $=\gamma$-aminobutyric acid

$\mathrm{GDH}=$ Glutamate dehydrogenase

GLT = Glutamate transporter for rodents

L-Glu = Glutamate

$\mathrm{IC}_{50}=$ Half maximal inhibitory concentration

mGluR $=$ Metabotropic glutamate receptors

mSOD1 = Mutant superoxide dismutase 1

NMDA $=N$-methyl-D-aspartate

PDB $=$ Protein data bank

PI3K = Phosphatidylinositol 3-kinase

$\mathrm{PKC}=$ Protein kinase $\mathrm{C}$ 
QSAR $=$ Quantitative structure activity relationship

ROS $=$ Reactive oxygene species

SALS $=$ Sporadic ALS

SAR $=$ Structure-activity relationship

TRPC5 $=$ Transient receptor potential channel C5

\section{REFERENCES}

[1] Rowland, L.P.; Shneider, N.A. Amyotrophic lateral sclerosis. $N$. Engl. J. Med., 2001, 344(22), 1688-1700.

[2] Logroscino, G.; Traynor, B.J.; Hardiman, O.; Chio, A.; Mitchell, D.; Swingler, R.J.; Millul, A.; Benn, E.; Beghi, E. Incidence of amyotrophic lateral sclerosis in Europe. J. Neurol. Neurosurg. Psychiatr., 2010, 81(4), 385-390.

[3] Gordon, P.H.; Wang, Y.; Doorish, C.; Lewis, M.; Battista, V.; Mitsumoto, H.; Marder, K. A screening assessment of cognitive impairment in patients with ALS. Amyotroph. Lateral Scler., 2007, $8(6), 362-365$.

[4] Goetz, C.G. Chapter 15: Jean-Martin Charcot and the anatomoclinical method of neurology. Handb. Clin. Neurol., 2010, 95, 203212.

[5] Gordon, P.H.; Cheng, B.; Katz, I.B.; Pinto, M.; Hays, A.P.; Mitsumoto, H.; Rowland, L.P. The natural history of primary lateral sclerosis. Neurology, 2006, 66(5), 647-653.

[6] Sachs, C.; Conradi, S.; Kaijser, L. Autonomic function in amyotrophic lateral sclerosis: a study of cardiovascular responses. Acta Neurol. Scand., 1985, 71(5), 373-378.

[7] Plaitakis, A.; Caroscio, J.T. Abnormal glutamate metabolism in amyotrophic lateral sclerosis. Ann. Neurol., 1987, 22(5), 575-579.

[8] Rothstein, J.D.; Martin, L.J.; Kuncl, R.W. Decreased glutamate transport by the brain and spinal cord in amyotrophic lateral sclerosis. N. Engl. J. Med., 1992, 326(22), 1464-1468.

[9] Roisen, F.J.; Bartfeld, H.; Donnenfeld, H.; Baxter, J. Neuron specific in vitro cytotoxicity of sera from patients with amyotrophic lateral sclerosis. Muscle Nerve, 1982, 5(1), 48-53.

[10] Rothstein, J.D. Excitotoxic mechanisms in the pathogenesis of amyotrophic lateral sclerosis. Adv. Neurol., 1995, 68, 7-20; discussion 21-27.

[11] Rothstein, J.D. Excitotoxicity and neurodegeneration in amyotrophic lateral sclerosis. Clin. Neurosci., 1995, 3(6), 348-359.

[12] Lacomblez, L.; Bensimon, G.; Leigh, P.N.; Guillet, P.; Meininger, V. Dose-ranging study of riluzole in amyotrophic lateral sclerosis. Amyotrophic Lateral Sclerosis/Riluzole Study Group II. Lancet, 1996, 347(9013), 1425-1431.

[13] Areosa, S.A.; Sherriff, F. Memantine for dementia. Cochrane Database Syst. Rev., 2003, 3, CD003154.

[14] Gordon, P.H.; Meininger, V. How can we improve clinical trials in amyotrophic lateral sclerosis? Nat. Rev. Neurol., 2011, 7(11), 650654.

[15] Allen, N.J.; Barres, B.A. Signaling between glia and neurons: focus on synaptic plasticity. Curr. Opin. Neurobiol., 2005, 15(5), 542548.

[16] Fields, R.D.; Stevens-Graham, B. New insights into neuron-glia communication. Science, 2002, 298(5593), 556-562.

[17] Rodriguez-Rodriguez, P.; Almeida, A.; Bolanos, J.P. Brain energy metabolism in glutamate-receptor activation and excitotoxicity: role for $\mathrm{APC} / \mathrm{C}-\mathrm{Cdh} 1$ in the balance glycolysis/pentose phosphate pathway. Neurochem. Int., 2013, 62(5), 750-756.

[18] Hollmann, M.; Heinemann, S. Cloned glutamate receptors. Annu. Rev. Neurosci., 1994, 17, 31-108.

[19] Bettler, B.; Mulle, C. Review: neurotransmitter receptors. II. AMPA and kainate receptors. Neuropharmacology, 1995, 34(2), 123-139.

[20] Pin, J.P.; Gomeza, J.; Joly, C.; Bockaert, J. The metabotropic glutamate receptors: their second intracellular loop plays a critical role in the G-protein coupling specificity. Biochem. Soc. Trans., 1995, 23(1), 91-96.

[21] Pin, J.P.; Duvoisin, R. The metabotropic glutamate receptors: structure and functions. Neuropharmacology, 1995, 34(1), 1-26.

[22] Pin, J.P.; Bockaert, J. Get receptive to metabotropic glutamate receptors. Curr. Opin. Neurobiol., 1995, 5(3), 342-349.
[23] Hume, R.I.; Dingledine, R.; Heinemann, S.F. Identification of a site in glutamate receptor subunits that controls calcium permeability. Science, 1991, 253(5023), 1028-1031.

[24] Hollmann, M.; Hartley, M.; Heinemann, S. Ca2+ permeability of KA-AMPA--gated glutamate receptor channels depends on subunit composition. Science, 1991, 252(5007), 851-853.

[25] Van Den Bosch, L.; Van Damme, P.; Bogaert, E.; Robberecht, W. The role of excitotoxicity in the pathogenesis of amyotrophic lateral sclerosis. Biochim. Biophys. Acta, 2006, 1762(11-12), 10681082

[26] Collingridge, G.L.; Lester, R.A. Excitatory amino acid receptors in the vertebrate central nervous system. Pharmacol. Rev., 1989, 41(2), 143-210.

[27] Nicoll, R.A.; Malenka, R.C. Expression mechanisms underlying NMDA receptor-dependent long-term potentiation. Ann. N. Y. Acad. Sci., 1999, 868, 515-525.

[28] Kutsuwada, T.; Kashiwabuchi, N.; Mori, H.; Sakimura, K.; Kushiya, E.; Araki, K.; Meguro, H.; Masaki, H.; Kumanishi, T.; Arakawa, M.; Mishina, M. Molecular diversity of the NMDA receptor channel. Nature, 1992, 358(6381), 36-41.

[29] Monyer, H.; Burnashev, N.; Laurie, D.J.; Sakmann, B.; Seeburg, P.H. Developmental and regional expression in the rat brain and functional properties of four NMDA receptors. Neuron, 1994, 12(3), 529-540.

[30] Kuner, T.; Wollmuth, L.P.; Karlin, A.; Seeburg, P.H.; Sakmann, B. Structure of the NMDA receptor channel M2 segment inferred from the accessibility of substituted cysteines. Neuron, 1996, 17(2), 343-352

[31] Lerma, J.; Marques, J.M. Kainate receptors in health and disease. Neuron, 2013, 80(2), 292-311.

[32] Pizzi, M.; Benarese, M.; Boroni, F.; Goffi, F.; Valerio, A.; Spano, P.F. Neuroprotection by metabotropic glutamate receptor agonists on kainate-induced degeneration of motor neurons in spinal cord slices from adult rat. Neuropharmacology, 2000, 39(5), 903-910.

[33] Anneser, J.M.; Horstmann, S.; Weydt, P.; Borasio, G.D. Activation of metabotropic glutamate receptors delays apoptosis of chick embryonic motor neurons in vitro. Neuroreport, 1998, 9(9), 20392043.

[34] Tanaka, K.; Watase, K.; Manabe, T.; Yamada, K.; Watanabe, M.; Takahashi, K.; Iwama, H.; Nishikawa, T.; Ichihara, N.; Kikuchi, T.; Okuyama, S.; Kawashima, N.; Hori, S.; Takimoto, M.; Wada, K. Epilepsy and exacerbation of brain injury in mice lacking the glutamate transporter GLT-1. Science, 1997, 276(5319), 16991702

[35] O'Kane, R.L.; Martinez-Lopez, I.; DeJoseph, M.R.; Vina, J.R.; Hawkins, R.A. $\mathrm{Na}(+)$-dependent glutamate transporters (EAAT1, EAAT2, and EAAT3) of the blood-brain barrier. A mechanism for glutamate removal. J. Biol. Chem., 1999, 274(45), 31891-31895.

[36] Vacher, H.; Mohapatra, D.P.; Trimmer, J.S. Localization and targeting of voltage-dependent ion channels in mammalian central neurons. Physiol. Rev., 2008, 88(4), 1407-1447.

[37] Kawahara, Y.; Ito, K.; Sun, H.; Ito, M.; Kanazawa, I.; Kwak, S. GluR4c, an alternative splicing isoform of GluR4, is abundantly expressed in the adult human brain. Brain Res. Mol. Brain Res., 2004, 127(1-2), 150-155.

[38] Rothstein, J.D.; Van Kammen, M.; Levey, A.I.; Martin, L.J.; Kuncl, R.W. Selective loss of glial glutamate transporter GLT-1 in amyotrophic lateral sclerosis. Ann. Neurol., 1995, 38(1), 73-84.

[39] Rothstein, J.D.; Dykes-Hoberg, M.; Pardo, C.A.; Bristol, L.A.; Jin, L.; Kuncl, R.W.; Kanai, Y.; Hediger, M.A.; Wang, Y.; Schielke, J.P.; Welty, D.F. Knockout of glutamate transporters reveals a major role for astroglial transport in excitotoxicity and clearance of glutamate. Neuron, 1996, 16(3), 675-686.

[40] Bartels, C.; Mertens, N.; Hofer, S.; Merboldt, K.D.; Dietrich, J.; Frahm, J.; Ehrenreich, H. Callosal dysfunction in amyotrophic lateral sclerosis correlates with diffusion tensor imaging of the central motor system. Neuromuscul. Disord., 2008, 18(5), 398-407.

[41] Trotti, D.; Rolfs, A.; Danbolt, N.C.; Brown, R.H., Jr.; Hediger, M.A. SOD1 mutants linked to amyotrophic lateral sclerosis selectively inactivate a glial glutamate transporter. Nat. Neurosci., 1999, 2(9), 848

[42] Rothstein, J.D.; Patel, S.; Regan, M.R.; Haenggeli, C.; Huang, Y.H.; Bergles, D.E.; Jin, L.; Dykes Hoberg, M.; Vidensky, S.; Chung, D.S.; Toan, S.V.; Bruijn, L.I.; Su, Z.Z.; Gupta, P.; Fisher, P.B. Beta-lactam antibiotics offer neuroprotection by increasing glutamate transporter expression. Nature, 2005, 433(7021), 73-77. 
[43] Guo, H.; Lai, L.; Butchbach, M.E.; Stockinger, M.P.; Shan, X.; Bishop, G.A.; Lin, C.L. Increased expression of the glial glutamate transporter EAAT2 modulates excitotoxicity and delays the onset but not the outcome of ALS in mice. Hum. Mol. Genet., 2003, 12(19), 2519-2532.

[44] Dunlop, J.; Beal McIlvain, H.; She, Y.; Howland, D.S. Impaired spinal cord glutamate transport capacity and reduced sensitivity to riluzole in a transgenic superoxide dismutase mutant rat model of amyotrophic lateral sclerosis. J. Neurosci., 2003, 23(5), 1688-1696.

[45] Howland, D.S.; Liu, J.; She, Y.; Goad, B.; Maragakis, N.J.; Kim, B.; Erickson, J.; Kulik, J.; DeVito, L.; Psaltis, G.; DeGennaro, L.J.; Cleveland, D.W.; Rothstein, J.D. Focal loss of the glutamate transporter EAAT2 in a transgenic rat model of SOD1 mutantmediated amyotrophic lateral sclerosis (ALS). Proc. Natl. Acad. Sci. USA, 2002, 99(3), 1604-1609.

[46] Bruijn, L.I.; Becher, M.W.; Lee, M.K.; Anderson, K.L.; Jenkins, N.A.; Copeland, N.G.; Sisodia, S.S.; Rothstein, J.D.; Borchelt, D.R.; Price, D.L.; Cleveland, D.W. ALS-linked SOD1 mutant G85R mediates damage to astrocytes and promotes rapidly progressive disease with SOD1-containing inclusions. Neuron, 1997, 18(2), 327-338.

[47] Giribaldi, F.; Milanese, M.; Bonifacino, T.; Anna Rossi, P.I.; Di Prisco, S.; Pittaluga, A.; Tacchetti, C.; Puliti, A.; Usai, C.; Bonanno, G. Group I metabotropic glutamate autoreceptors induce abnormal glutamate exocytosis in a mouse model of amyotrophic lateral sclerosis. Neuropharmacology, 2013, 66, 253-263.

[48] Poulopoulou, C.; Davaki, P.; Koliaraki, V.; Kolovou, D.; Markakis, I.; Vassilopoulos, D. Reduced expression of metabotropic glutamate receptor 2mRNA in T cells of ALS patients. Ann. Neurol., 2005, 58(6), 946-949.

[49] Aronica, E.; Catania, M.V.; Geurts, J.; Yankaya, B.; Troost, D. Immunohistochemical localization of group I and II metabotropic glutamate receptors in control and amyotrophic lateral sclerosis human spinal cord: upregulation in reactive astrocytes. Neuroscience, 2001, 105(2), 509-520.

[50] Rossi, B.; Maton, G.; Collin, T. Calcium-permeable presynaptic AMPA receptors in cerebellar molecular layer interneurones. $J$. Physiol., 2008, 586(Pt 21), 5129-5145.

[51] Cheah, B.C.; Kiernan, M.C. Dexpramipexole, the R(+) enantiomer of pramipexole, for the potential treatment of amyotrophic lateral sclerosis. IDrugs, 2010, 13(12), 911-920.

[52] Rothstein, J.D.; Tsai, G.; Kuncl, R.W.; Clawson, L.; Cornblath, D.R.; Drachman, D.B.; Pestronk, A.; Stauch, B.L.; Coyle, J.T. Abnormal excitatory amino acid metabolism in amyotrophic lateral sclerosis. Ann. Neurol., 1990, 28(1), 18-25.

[53] Shaw, P.J.; Forrest, V.; Ince, P.G.; Richardson, J.P.; Wastell, H.J. $\mathrm{CSF}$ and plasma amino acid levels in motor neuron disease: elevation of CSF glutamate in a subset of patients. Neurodegeneration, 1995, 4(2), 209-216.

[54] Spreux-Varoquaux, O.; Bensimon, G.; Lacomblez, L.; Salachas, F.; Pradat, P.F.; Le Forestier, N.; Marouan, A.; Dib, M.; Meininger, V. Glutamate levels in cerebrospinal fluid in amyotrophic lateral sclerosis: a reappraisal using a new HPLC method with coulometric detection in a large cohort of patients. J. Neurol. Sci., 2002, 193(2), 73-78.

[55] Gredal, O.; Moller, S.E. Effect of branched-chain amino acids on glutamate metabolism in amyotrophic lateral sclerosis. J. Neurol. Sci., 1995, 129(1), 40-43.

[56] Ilzecka, J.; Stelmasiak, Z.; Solski, J.; Wawrzycki, S.; Szpetnar, M. Plasma amino acids concentration in amyotrophic lateral sclerosis patients. Amino Acids, 2003, 25(1), 69-73.

[57] Perry, T.L.; Krieger, C.; Hansen, S.; Eisen, A. Amyotrophic lateral sclerosis: amino acid levels in plasma and cerebrospinal fluid. Ann. Neurol., 1990, 28(1), 12-17.

[58] Wuolikainen, A.; Moritz, T.; Marklund, S.L.; Antti, H.; Andersen, P.M. Disease-related changes in the cerebrospinal fluid metabolome in amyotrophic lateral sclerosis detected by GC/TOFMS. PLoS One, 2011, 6(4), e17947.

[59] Kumar, A.; Bala, L.; Kalita, J.; Misra, U.K.; Singh, R.L.; Khetrapal, C.L.; Babu, G.N. Metabolomic analysis of serum by (1) H NMR spectroscopy in amyotrophic lateral sclerosis. Clin. Chim. Acta, 2010, 411(7-8), 563-567.

[60] Blasco, H.; Corcia, P.; Pradat, P.F.; Bocca, C.; Gordon, P.H.; Veyrat-Durebex, C.; Mavel, S.; Nadal-Desbarats, L.; Moreau, C.; Devos, D.; Andres, C.R.; Emond, P. Metabolomics in Cerebrospinal Fluid of Patients with Amyotrophic Lateral
Sclerosis: An Untargeted Approach via High-Resolution Mass Spectrometry. J. Proteome Res., 2013, 12(8), 3746-3754.

[61] Sasabe, J.; Miyoshi, Y.; Suzuki, M.; Mita, M.; Konno, R.; Matsuoka, M.; Hamase, K.; Aiso, S. D-amino acid oxidase controls motoneuron degeneration through D-serine. Proc. Natl. Acad. Sci. USA, 2012, 109(2), 627-632.

[62] Sasabe, J.; Chiba, T.; Yamada, M.; Okamoto, K.; Nishimoto, I.; Matsuoka, M.; Aiso, S. D-serine is a key determinant of glutamate toxicity in amyotrophic lateral sclerosis. EMBO J., 2007, 26(18), 4149-4159.

[63] Mitchell, J.; Paul, P.; Chen, H.J.; Morris, A.; Payling, M.; Falchi, M.; Habgood, J.; Panoutsou, S.; Winkler, S.; Tisato, V.; Hajitou, A.; Smith, B.; Vance, C.; Shaw, C.; Mazarakis, N.D.; de Belleroche, J. Familial amyotrophic lateral sclerosis is associated with a mutation in D-amino acid oxidase. Proc. Natl. Acad. Sci. USA, 2010, 107(16), 7556-7561.

[64] Lipton, S.A.; Rosenberg, P.A. Excitatory amino acids as a final common pathway for neurologic disorders. N. Engl. J. Med., 1994, 330(9), 613-622.

[65] Tapia, R.; Medina-Ceja, L.; Pena, F. On the relationship between extracellular glutamate, hyperexcitation and neurodegeneration, in vivo. Neurochem. Int., 1999, 34(1), 23-31.

[66] Meldrum, B.S. Glutamate as a neurotransmitter in the brain: review of physiology and pathology. J. Nutr., 2000, 130(4S Suppl), 1007S-1015S.

[67] Grosskreutz, J.; Van Den Bosch, L.; Keller, B.U. Calcium dysregulation in amyotrophic lateral sclerosis. Cell Calcium., 2010, 47(2), 165-174.

[68] Scott, S.; Kranz, J.E.; Cole, J.; Lincecum, J.M.; Thompson, K.; Kelly, N.; Bostrom, A.; Theodoss, J.; Al-Nakhala, B.M.; Vieira, F.G.; Ramasubbu, J.; Heywood, J.A. Design, power, and interpretation of studies in the standard murine model of ALS. Amyotroph. Lateral. Scler., 2008, 9(1), 4-15.

[69] Gordon, P.H. Amyotrophic Lateral Sclerosis: An update for 2013 Clinical Features, Pathophysiology, Management and Therapeutic Trials. Aging Dis., 2013, 4(5), 295-310.

[70] Mitsumoto, H.; Gordon, P.; Kaufmann, P.; Gooch, C.L.; Przedborski, S.; Rowland, L.P. Randomized control trials in ALS lessons learned. Amyotroph. Lateral. Scler. Other Motor. Neuron. Disord., 2004, 5 Suppl 1,8-13.

[71] Buckingham, S.D.; Kwak, S.; Jones, A.K.; Blackshaw, S.E.; Sattelle, D.B. Edited GluR2, a gatekeeper for motor neurone survival? Bioessays, 2008, 30(11-12), 1185-1192.

[72] Barrie, E.S.; Smith, R.M.; Sanford, J.C.; Sadee, W. mRNA transcript diversity creates new opportunities for pharmacological intervention. Mol. Pharmacol., 2012, 81(5), 620-630.

[73] Jarmin, S.; Kymalainen, H.; Popplewell, L.; Dickson, G. New developments in the use of gene therapy to treat Duchenne muscular dystrophy. Expert Opin. Biol. Ther., 2014, 14(2), 209230.

[74] Streit, A.K.; Decher, N. A-to-I RNA editing modulates the pharmacology of neuronal ion channels and receptors. Biochem. (Mosc.), 2011, 76(8), 890-899.

[75] Werry, T.D.; Loiacono, R.; Sexton, P.M.; Christopoulos, A. RNA editing of the serotonin 5HT2C receptor and its effects on cell signalling, pharmacology and brain function. Pharmacol. Ther., 2008, $119(1), 7-23$.

[76] Durrant, J.D.; McCammon, J.A. Towards the development of novel Trypanosoma brucei RNA editing ligase 1 inhibitors. $B M C$ Pharmacol., 2011, 11, 9.

[77] Durrant, J.D.; Hall, L.; Swift, R.V.; Landon, M.; Schnaufer, A.; Amaro, R.E. Novel naphthalene-based inhibitors of Trypanosoma brucei RNA editing ligase 1. PLoS. Negl. Trop. Dis., 2010, 4(8), e803.

[78] Sawada, J.; Yamashita, T.; Aizawa, H.; Aburakawa, Y.; Hasebe, N.; Kwak, S. Effects of antidepressants on GluR2 Q/R site-RNA editing in modified HeLa cell line. Neurosci. Res., 2009, 64(3), 251-258.

[79] Collingridge, G.L.; Singer, W. Excitatory amino acid receptors and synaptic plasticity. Trends Pharmacol. Sci., 1990, 11(7), 290-296.

[80] Danysz, W.; Zajaczkowski, W.; Parsons, C.G. Modulation of learning processes by ionotropic glutamate receptor ligands. Behav. Pharmacol., 1995, 6(5 And 6), 455-474.

[81] Colton, C.K.; Kong, Q.; Lai, L.; Zhu, M.X.; Seyb, K.I.; Cuny, G.D.; Xian, J.; Glicksman, M.A.; Lin, C.L. Identification of translational activators of glial glutamate transporter EAAT2 
through cell-based high-throughput screening: an approach to prevent excitotoxicity. J. Biomol. Screen., 2010, 15(6), 653-662.

[82] Mao, J. Glutamate transporter: an unexpected target for some antibiotics. Mol. Pain., 2005, $1,5$.

[83] Fontana, A.C.; de Oliveira Beleboni, R.; Wojewodzic, M.W.; Ferreira Dos Santos, W.; Coutinho-Netto, J.; Grutle, N.J.; Watts, S.D.; Danbolt, N.C.; Amara, S.G. Enhancing glutamate transport: mechanism of action of Parawixin1, a neuroprotective compound from Parawixia bistriata spider venom. Mol. Pharmacol., 2007, 72(5), 1228-1237.

[84] Torres-Salazar, D.; Fahlke, C. Parawixin1: a spider toxin opening new avenues for glutamate transporter pharmacology. Mol. Pharmacol., 2007, 72(5), 1100-1102.

[85] Xing, X.; Chang, L.C.; Kong, Q.; Colton, C.K.; Lai, L.; Glicksman, M.A.; Lin, C.L.; Cuny, G.D. Structure-activity relationship study of pyridazine derivatives as glutamate transporter EAAT2 activators. Bioorg. Med. Chem. Lett., 2011, 21(19), 5774-5777.

[86] Lin, C.L.; Kong, Q.; Cuny, G.D.; Glicksman, M.A. Glutamate transporter EAAT2: a new target for the treatment of neurodegenerative diseases. Future Med. Chem., 2012, 4(13), $1689-1700$.

[87] Luethi, E.; Nguyen, K.T.; Burzle, M.; Blum, L.C.; Suzuki, Y.; Hediger, M.; Reymond, J.L. Identification of selective norbornanetype aspartate analogue inhibitors of the glutamate transporter 1 (GLT-1) from the chemical universe generated database (GDB). $J$. Med. Chem., 2010, 53(19), 7236-7250.

[88] Wu, J.; Lee, M.R.; Choi, S.; Kim, T.; Choi, D.S. ENT1 regulates ethanol-sensitive EAAT2 expression and function in astrocytes. Alcohol Clin. Exp. Res., 2010, 34(6), 1110-1117.

[89] Bunch, L.; Gefflaut, T.; Alaux, S.; Sagot, E.; Nielsen, B.; Pickering, D.S. Pharmacological characterization of (4R)-alkyl glutamate analogues at the ionotropic glutamate receptors--focus on subtypes iGlu(5-7). Eur. J. Pharmacol., 2009, 609(1-3), 1-4.

[90] Alaux, S.; Kusk, M.; Sagot, E.; Bolte, J.; Jensen, A.A.; BraunerOsborne, H.; Gefflaut, T.; Bunch, L. Chemoenzymatic synthesis of a series of 4-substituted glutamate analogues and pharmacological characterization at human glutamate transporters subtypes 1-3. J. Med. Chem., 2005, 48(25), 7980-7992.

[91] Sagot, E.; Pickering, D.S.; Pu, X.; Umberti, M.; Stensbol, T.B.; Nielsen, B.; Chapelet, M.; Bolte, J.; Gefflaut, T.; Bunch, L. Chemo-enzymatic synthesis of a series of 2,4-syn-functionalized (S)-glutamate analogues: new insight into the structure-activity relation of ionotropic glutamate receptor subtypes 5,6 , and $7 . J$. Med. Chem., 2008, 5l(14), 4093-4103.

[92] Assaf, Z.; Larsen, A.P.; Venskutonyte, R.; Han, L.; Abrahamsen, B.; Nielsen, B.; Gajhede, M.; Kastrup, J.S.; Jensen, A.A.; Pickering, D.S.; Frydenvang, K.; Gefflaut, T.; Bunch, L. Chemoenzymatic synthesis of new 2,4-syn-functionalized (S)glutamate analogues and structure-activity relationship studies at ionotropic glutamate receptors and excitatory amino acid transporters. J. Med. Chem., 2013, 56(4), 1614-1628.

[93] Bunch, L.; Pickering, D.S.; Gefflaut, T.; Vinatier, V.; Helaine, V.; Amir, A.; Nielsen, B.; Jensen, A.A. 4,4-Dimethyl- and diastereomeric 4-hydroxy-4-methyl- (2S)-glutamate analogues display distinct pharmacological profiles at ionotropic glutamate receptors and excitatory amino acid transporters. ChemMedChem, 2009, 4(11), 1925-1929.

[94] Bensimon, G.; Ludolph, A.; Agid, Y.; Vidailhet, M.; Payan, C.; Leigh, P.N. Riluzole treatment, survival and diagnostic criteria in Parkinson plus disorders: the NNIPPS study. Brain, 2009, 132(Pt 1), 156-171.

[95] Pittenger, C.; Coric, V.; Banasr, M.; Bloch, M.; Krystal, J.H.; Sanacora, G. Riluzole in the treatment of mood and anxiety disorders. CNS Drugs, 2008, 22(9), 761-786.

[96] Doble, A. The pharmacology and mechanism of action of riluzole. Neurology, 1996, 47(6 Suppl 4), S233-241.

[97] Bensimon, G.; Lacomblez, L.; Meininger, V. A controlled trial of riluzole in amyotrophic lateral sclerosis. ALS/Riluzole Study Group. N. Engl. J. Med., 1994, 330(9), 585-591.

[98] Jimonet, P.; Audiau, F.; Barreau, M.; Blanchard, J.C.; Boireau, A.; Bour, Y.; Coleno, M.A.; Doble, A.; Doerflinger, G.; Huu, C.D.; Donat, M.H.; Duchesne, J.M.; Ganil, P.; Gueremy, C.; Honor, E.; Just, B.; Kerphirique, R.; Gontier, S.; Hubert, P.; Laduron, P.M.; Le Blevec, J.; Meunier, M.; Miquet, J.M.; Nemecek, C.; Pasquet, M.; Piot, O.; Pratt, J.; Rataud, J.; Reibaud, M.; Stutzmann, J.M.; Mignani, S. Riluzole series. Synthesis and in vivo "antiglutamate" activity of 6-substituted-2-benzothiazolamines and 3-substituted-2imino-benzothiazolines. J. Med. Chem., 1999, 42(15), 2828-2843.

[99] Jimonet, P.; Barreau, M.; Blanchard, J.C.; Boireau, A.; Doble, A.; Laduron, P.; Lavayre, J.; Malgouris, C.; Piot, O.; Pratt, J.; Rataud, J.; Reibaud, M.; Mignani, S.; Stutzmann, J.-M. Synthesis, anticonvulsant and neuroprotective activities of RP 66055, a riluzole derivative. Bioorg. Med. Chem., 1994, 2(8), 793-798.

[100] Knox, C.; Law, V.; Jewison, T.; Liu, P.; Ly, S.; Frolkis, A.; Pon, A.; Banco, K.; Mak, C.; Neveu, V.; Djoumbou, Y.; Eisner, R.; Guo, A.C.; Wishart, D.S. DrugBank 3.0: a comprehensive resource for 'omics' research on drugs. Nucleic. Acids Res., 2011, 39(Database issue), D1035-1041.

[101] Sierra Bello, O.; Gonzalez, J.; Capani, F.; Barreto, G.E. In silico docking reveals possible Riluzole binding sites on Nav1.6 sodium channel: implications for amyotrophic lateral sclerosis therapy. $J$. Theor. Biol., 2012, 315, 53-63.

[102] Miloushev, V.Z.; Levine, J.A.; Arbing, M.A.; Hunt, J.F.; Pitt, G.S.; Palmer, A.G. 3rd, Solution structure of the NaV1.2 C-terminal EFhand domain. J. Biol. Chem., 2009, 284(10), 6446-6454.

[103] Sanderink, G.J.; Bournique, B.; Stevens, J.; Petry, M.; Martinet, M. Involvement of human CYP1A isoenzymes in the metabolism and drug interactions of riluzole in vitro. J. Pharmacol. Exp. Ther. 1997, 282(3), 1465-1472.

[104] Groeneveld, G.J.; Veldink, J.H.; van der Tweel, I.; Kalmijn, S.; Beijer, C.; de Visser, M.; Wokke, J.H.; Franssen, H.; van den Berg, L.H. A randomized sequential trial of creatine in amyotrophic lateral sclerosis. Ann. Neurol., 2003, 53(4), 437-445.

[105] McDonnell, M.E.; Vera, M.D.; Blass, B.E.; Pelletier, J.C.; King, R.C.; Fernandez-Metzler, C.; Smith, G.R.; Wrobel, J.; Chen, S.; Wall, B.A.; Reitz, A.B. Riluzole prodrugs for melanoma and ALS: design, synthesis, and in vitro metabolic profiling. Bioorg. Med. Chem., 2012, 20(18), 5642-5648.

[106] Hassan, M.Z.; Khan, S.A.; Amir, M. Design, synthesis and evaluation of $\mathrm{N}$-(substituted benzothiazol-2-yl)amides as anticonvulsant and neuroprotective. Eur. J. Med. Chem., 2012, 58, 206-213.

[107] Amnerkar, N.D.; Bhusari, K.P. Synthesis, anticonvulsant activity and 3D-QSAR study of some prop-2-eneamido and 1-acetylpyrazolin derivatives of aminobenzothiazole. Eur. J. Med. Chem., 2010, 45(1), 149-159.

[108] Wu, Y.; Satkunendrarajah, K.; Teng, Y.; Chow, D.S.; Buttigieg, J.; Fehlings, M.G. Delayed post-injury administration of riluzole is neuroprotective in a preclinical rodent model of cervical spinal cord injury. J. Neurotrauma, 2013, 30(6), 441-452.

[109] Milane, A.; Tortolano, L.; Fernandez, C.; Bensimon, G.; Meininger, V.; Farinotti, R. Brain and plasma riluzole pharmacokinetics: effect of minocycline combination. J. Pharm. Pharm. Sci., 2009, 12(2), 209-217.

[110] Milane, A.; Fernandez, C.; Vautier, S.; Bensimon, G.; Meininger, V.; Farinotti, R. Minocycline and riluzole brain disposition interactions with p-glycoprotein at the blood-brain barrier. $J$ Neurochem., 2007, 103(1), 164-173.

[111] Maltese, A.; Maugeri, F.; Drago, F.; Bucolo, C. Simple determination of riluzole in rat brain by high-performance liquid chromatography and spectrophotometric detection. J. Chromatogr. B. Analyt. Technol. Biomed. Life Sci., 2005, 817(2), 331-334.

[112] Colovic, M.; Zennaro, E.; Caccia, S. Liquid chromatographic assay for riluzole in mouse plasma and central nervous system tissues. $J$. Chromatogr. B. Analyt. Technol. Biomed. Life Sci., 2004, 803(2), 305-309.

[113] Bruno, R.; Vivier, N.; Montay, G.; Le Liboux, A.; Powe, L.K. Delumeau, J.C.; Rhodes, G.R. Population pharmacokinetics of riluzole in patients with amyotrophic lateral sclerosis. Clin. Pharmacol. Ther., 1997, 62(5), 518-526.

[114] Chow, D.S.; Teng, Y.; Toups, E.G.; Aarabi, B.; Harrop, J.S.; Shaffrey, C.I.; Johnson, M.M.; Boakye, M.; Frankowski, R.F.; Fehlings, M.G.; Grossman, R.G. Pharmacology of riluzole in acute spinal cord injury. J. Neurosurg. Spine, 2012, $17(1$ Suppl), 129140.

[115] Frizzo, M.E.; Dall'Onder, L.P.; Dalcin, K.B.; Souza, D.O. Riluzole enhances glutamate uptake in rat astrocyte cultures. Cell. Mol. Neurobiol., 2004, 24(1), 123-128.

[116] Azbill, R.D.; Mu, X.; Springer, J.E. Riluzole increases high-affinity glutamate uptake in rat spinal cord synaptosomes. Brain Res. 2000, $871(2), 175-180$ 
[117] Cheah, B.C.; Vucic, S.; Krishnan, A.V.; Kiernan, M.C. Riluzole, neuroprotection and amyotrophic lateral sclerosis. Curr. Med. Chem., 2010, 17(18), 1942-1199.

[118] Bellingham, M.C. A review of the neural mechanisms of action and clinical efficiency of riluzole in treating amyotrophic lateral sclerosis: what have we learned in the last decade? CNS Neurosci. Ther., 2011, 17(1), 4-31.

[119] Prakriya, M.; Mennerick, S. Selective depression of low-release probability excitatory synapses by sodium channel blockers. Neuron, 2000, 26(3), 671-682.

[120] Lamanauskas, N.; Nistri, A. Riluzole blocks persistent $\mathrm{Na}+$ and $\mathrm{Ca} 2+$ currents and modulates release of glutamate via presynaptic NMDA receptors on neonatal rat hypoglossal motoneurons in vitro. Eur. J. Neurosci., 2008, 27(10), 2501-2514.

[121] He, Y.; Zorumski, C.F.; Mennerick, S. Contribution of presynaptic $\mathrm{Na}(+)$ channel inactivation to paired-pulse synaptic depression in cultured hippocampal neurons. J. Neurophysiol., 2002, 87(2), 925936.

[122] Centonze, D.; Calabresi, P.; Pisani, A.; Marinelli, S.; Marfia, G.A.; Bernardi, G. Electrophysiology of the neuroprotective agent riluzole on striatal spiny neurons. Neuropharmacology, 1998, 37(8), 1063-1070.

[123] Benavides, J.; Camelin, J.C.; Mitrani, N.; Flamand, F.; Uzan, A.; Legrand, J.J.; Gueremy, C.; Le Fur, G. 2-Amino-6trifluoromethoxy benzothiazole, a possible antagonist of excitatory amino acid neurotransmission--II. Biochemical properties. Neuropharmacology, 1985, 24(11), 1085-1092.

[124] Urbani, A.; Belluzzi, O. Riluzole inhibits the persistent sodium current in mammalian CNS neurons. Eur. J. Neurosci., 2000, 12(10), 3567-3574.

[125] van Zundert, B.; Peuscher, M.H.; Hynynen, M.; Chen, A.; Neve, R.L.; Brown, R.H., Jr.; Constantine-Paton, M.; Bellingham, M.C. Neonatal neuronal circuitry shows hyperexcitable disturbance in a mouse model of the adult-onset neurodegenerative disease amyotrophic lateral sclerosis. J. Neurosci., 2008, 28(43), 1086410874.

[126] Kuo, J.J.; Lee, R.H.; Zhang, L.; Heckman, C.J. Essential role of the persistent sodium current in spike initiation during slowly rising inputs in mouse spinal neurones. J. Physiol., 2006, 574(Pt 3), 819834.

[127] Cao, Y.J.; Dreixler, J.C.; Couey, J.J.; Houamed, K.M. Modulation of recombinant and native neuronal SK channels by the neuroprotective drug riluzole. Eur. J. Pharmacol., 2002, 449(1-2), 47-54.

[128] Dimitriadi, M.; Kye, M.J.; Kalloo, G.; Yersak, J.M.; Sahin, M.; Hart, A.C. The neuroprotective drug riluzole acts via small conductance $\mathrm{Ca} 2+$-activated $\mathrm{K}+$ channels to ameliorate defects in spinal muscular atrophy models. J. Neurosci., 2013, 33(15), 65576562.

[129] Huang, F.; Gallo, V. Gene structure of the rat kainate receptor subunit KA2 and characterization of an intronic negative regulatory region. J. Biol. Chem., 1997, 272(13), 8618-8627.

[130] Hubert, J.P.; Burgevin, M.C.; Terro, F.; Hugon, J.; Doble, A. Effects of depolarizing stimuli on calcium homeostasis in cultured rat motoneurones. Br. J. Pharmacol., 1998, 125(7), 1421-1428.

[131] Vucic, S.; Lin, C.S.; Cheah, B.C.; Murray, J.; Menon, P.; Krishnan, A.V.; Kiernan, M.C. Riluzole exerts central and peripheral modulating effects in amyotrophic lateral sclerosis. Brain, 2013, 136(Pt 5), 1361-1370.

[132] MacIver, M.B.; Amagasu, S.M.; Mikulec, A.A.; Monroe, F.A. Riluzole anesthesia: use-dependent block of presynaptic glutamate fibers. Anesthesiology, 1996, 85(3), 626-634.

[133] Pace, R.W.; Mackay, D.D.; Feldman, J.L.; Del Negro, C.A. Role of persistent sodium current in mouse preBotzinger Complex neurons and respiratory rhythm generation. J. Physiol., 2007, 580(Pt. 2), 485-496.

[134] Rammes, G.; Zieglgansberger, W.; Parsons, C.G. The fraction of activated N-methyl-D-aspartate receptors during synaptic transmission remains constant in the presence of the glutamate release inhibitor riluzole. J. Neural. Transm., 2008, 115(8), 11191126.

[135] Tazerart, S.; Viemari, J.C.; Darbon, P.; Vinay, L.; Brocard, F. Contribution of persistent sodium current to locomotor pattern generation in neonatal rats. J. Neurophysiol., 2007, 98(2), 613-628.
[136] Bellingham, M.C. Pre- and postsynaptic mechanisms underlying inhibition of hypoglossal motor neuron excitability by riluzole. $J$. Neurophysiol., 2013, 110(5), 1047-1061.

[137] Du, J.; Suzuki, K.; Wei, Y.; Wang, Y.; Blumenthal, R.; Chen, Z.; Falke, C.; Zarate, C.A., Jr.; Manji, H.K. The anticonvulsants lamotrigine, riluzole, and valproate differentially regulate AMPA receptor membrane localization: relationship to clinical effects in mood disorders. Neuropsychopharmacology, 2007, 32(4), 793-802.

[138] Hubert, J.P.; Delumeau, J.C.; Glowinski, J.; Premont, J.; Doble, A. Antagonism by riluzole of entry of calcium evoked by NMDA and veratridine in rat cultured granule cells: evidence for a dual mechanism of action. Br. J. Pharmacol., 1994, 113(1), 261-267.

[139] Noh, K.M.; Hwang, J.Y.; Shin, H.C.; Koh, J.Y. A novel neuroprotective mechanism of riluzole: direct inhibition of protein kinase C. Neurobiol. Dis., 2000, 7(4), 375-383.

[140] Rothstein, J.D. Therapeutic horizons for amyotrophic lateral sclerosis. Curr. Opin. Neurobiol., 1996, 6(5), 679-687.

[141] Fumagalli, E.; Funicello, M.; Rauen, T.; Gobbi, M.; Mennini, T. Riluzole enhances the activity of glutamate transporters GLAST, GLT1 and EAAC1. Eur. J. Pharmacol., 2008, 578(2-3), 171-176.

[142] Carbone, M.; Duty, S.; Rattray, M. Riluzole elevates GLT-1 activity and levels in striatal astrocytes. Neurochem. Int., 2012, 60(1), 31-38.

[143] Dall'Igna, O.P.; Bobermin, L.D.; Souza, D.O.; Quincozes-Santos, A. Riluzole increases glutamate uptake by cultured C6 astroglial cells. Int. J. Dev. Neurosci., 2013, 31(7), 482-486.

[144] Richter, J.M.; Schaefer, M.; Hill, K. Riluzole activates TRPC5 channels independently of PLC activity. Br. J. Pharmacol., 2014, 171(1), 158-170.

[145] Daniel, B.; Green, O.; Viskind, O.; Gruzman, A. Riluzole increases the rate of glucose transport in L6 myotubes and NSC-34 motor neuron-like cells via AMPK pathway activation. Amyotroph. Lateral. Scler. Frontotemporal. Degener., 2013, 14(5-6), 434-443.

[146] Bonnefont-Rousselot, D.; Lacomblez, L.; Jaudon, M.; Lepage, S.; Salachas, F.; Bensimon, G.; Bizard, C.; Doppler, V.; Delattre, J.; Meininger, V. Blood oxidative stress in amyotrophic lateral sclerosis. J. Neurol. Sci., 2000, 178(1), 57-62.

[147] Rinwa, P.; Jaggi, A.S.; Singh, N. Pharmacological investigation of memory restorative effect of riluzole in mice. Indian $J$. Pharmacol., 2012, 44(3), 366-371.

[148] Gottfried, C.; Tramontina, F.; Goncalves, D.; Goncalves, C.A.; Moriguchi, E.; Dias, R.D.; Wofchuk, S.T.; Souza, D.O. Glutamate uptake in cultured astrocytes depends on age: a study about the effect of guanosine and the sensitivity to oxidative stress induced by $\mathrm{H}(2) \mathrm{O}(2)$. Mech. Ageing Dev., 2002, 123(10), 1333-1340.

[149] Mehta, A.; Prabhakar, M.; Kumar, P.; Deshmukh, R.; Sharma, P.L. Excitotoxicity: bridge to various triggers in neurodegenerative disorders. Eur. J. Pharmacol., 2013, 698(1-3), 6-18.

[150] Trotti, D.; Danbolt, N.C.; Volterra, A. Glutamate transporters are oxidant-vulnerable: a molecular link between oxidative and excitotoxic neurodegeneration? Trends Pharmacol. Sci., 1998, 19, (8), 328-334.

[151] Jahn, K.; Schlesinger, F.; Jin, L.J.; Dengler, R.; Bufler, J.; Krampfl, K. Molecular mechanisms of interaction between the neuroprotective substance riluzole and GABA(A)-receptors. Naunyn. Schmiedebergs Arch. Pharmacol., 2008, 378(1), 53-63.

[152] Miller, R.G.; Mitchell, J.D.; Lyon, M.; Moore, D.H. Riluzole for amyotrophic lateral sclerosis (ALS)/motor neuron disease (MND). Cochrane Database Syst. Rev., 2002(2), CD001447.

[153] Lacomblez, L.; Bensimon, G.; Leigh, P.N.; Debove, C.; Bejuit, R.; Truffinet, P.; Meininger, V. Long-term safety of riluzole in amyotrophic lateral sclerosis. Amyotroph. Lateral Scler. Other Motor. Neuron. Disord., 2002, 3(1), 23-29.

[154] Taylor, C.P. Mechanisms of new antiepileptic drugs. Adv. Neurol., 1999, 79, 1011-1026.

[155] Andrews, C.O.; Fischer, J.H. Gabapentin: a new agent for the management of epilepsy. Ann. Pharmacother., 1994, 28(10), 11881196.

[156] Marson, A.G.; Kadir, Z.A.; Chadwick, D.W. New antiepileptic drugs: a systematic review of their efficacy and tolerability. $B M J$, 1996, 313(7066), 1169-1174.

[157] Beydoun, A. Monotherapy trials of new antiepileptic drugs. Epilepsia, 1997, 38 Suppl 9, S21-31.

[158] Taylor, C.P.; Gee, N.S.; Su, T.Z.; Kocsis, J.D.; Welty, D.F.; Brown, J.P.; Dooley, D.J.; Boden, P.; Singh, L. A summary of 
mechanistic hypotheses of gabapentin pharmacology. Epilepsy Res., 1998, 29(3), 233-249.

[159] Taylor, C.P.; Angelotti, T.; Fauman, E. Pharmacology and mechanism of action of pregabalin: the calcium channel alpha2delta (alpha2-delta) subunit as a target for antiepileptic drug discovery. Epilepsy Res., 2007, 73(2), 137-150.

[160] Satzinger, G. Antiepileptics from gamma-aminobutyric acid. Arzneimittelforschung, 1994, 44(3), 261-266.

[161] Lebedyeva, I.O.; Ostrov, D.A.; Neubert, J.; Steel, P.J.; Patel, K.; Sileno, S.M.; Goncalves, K.; Ibrahim, M.A.; Alamry, K.A.; Katritzky, A.R. Gabapentin hybrid peptides and bioconjugates. Bioorg. Med. Chem., 2014, 22(4), 1479-1486.

[162] Blakemore, D.C.; Bryans, J.S.; Carnell, P.; Chessum, N.E.; Field, M.J.; Kinsella, N.; Kinsora, J.K.; Osborne, S.A.; Williams, S.C. Synthesis and in vivo evaluation of 3-substituted gababutins. Bioorg. Med. Chem. Lett., 2010, 20(1), 362-365.

[163] Catarzi, D.; Colotta, V.; Varano, F. Competitive AMPA receptor antagonists. Med. Res. Rev., 2007, 27(2), 239-278.

[164] Kaufmann, P.; Lomen-Hoerth, C. ALS treatment strikes out while trying for a homer: the topiramate trial. Neurology, 2003, 61(4), 434-435

[165] Rogawski, M.A.; Loscher, W. The neurobiology of antiepileptic drugs for the treatment of nonepileptic conditions. Nat. Med., 2004, 10(7), 685-692.

[166] Schlicker, E.; Reimann, W.; Gothert, M. Gabapentin decreases monoamine release without affecting acetylcholine release in the brain. Arzneimittelforsch, 1985, 35(9), 1347-1349.

[167] McLean, M.J. Clinical pharmacokinetics of gabapentin. Neurology, 1994, 44(6 Suppl 5), S17-S22; discussion S31-12.

[168] Welty, D.F.; Schielke, G.P.; Rothstein, J.D. Potential treatment of amyotrophic lateral sclerosis with gabapentin: a hypothesis. Ann. Pharmacother., 1995, 29(11), 1164-1167.

[169] Goldlust, A.; Su, T.Z.; Welty, D.F.; Taylor, C.P.; Oxender, D.L. Effects of anticonvulsant drug gabapentin on the enzymes in metabolic pathways of glutamate and GABA. Epilepsy Res., 1995, 22(1), 1-11.

[170] Hutson, S.M.; Berkich, D.; Drown, P.; Xu, B.; Aschner, M.; LaNoue, K.F. Role of branched-chain aminotransferase isoenzymes and gabapentin in neurotransmitter metabolism. J. Neurochem., 1998, $71(2), 863-874$.

[171] Rothstein, J.D.; Kuncl, R.W. Neuroprotective strategies in a model of chronic glutamate-mediated motor neuron toxicity. $J$. Neurochem., 1995, 65(2), 643-651.

[172] Gurney, M.E.; Cutting, F.B.; Zhai, P.; Doble, A.; Taylor, C.P.; Andrus, P.K.; Hall, E.D. Benefit of vitamin E, riluzole, and gabapentin in a transgenic model of familial amyotrophic lateral sclerosis. Ann. Neurol., 1996, 39(2), 147-157.

[173] Kalra, S.; Cashman, N.R.; Caramanos, Z.; Genge, A.; Arnold, D.L. Gabapentin therapy for amyotrophic lateral sclerosis: lack of improvement in neuronal integrity shown by MR spectroscopy. AJNR Am. J. Neuroradiol., 2003, 24(3), 476-480.

[174] Miller, R.G.; Moore, D.; Young, L.A.; Armon, C.; Barohn, R.J.; Bromberg, M.B.; Bryan, W.W.; Gelinas, D.F.; Mendoza, M.C.; Neville, H.E.; Parry, G.J.; Petajan, J.H.; Ravits, J.M.; Ringel, S.P.; Ross, M.A. Placebo-controlled trial of gabapentin in patients with amyotrophic lateral sclerosis. WALS Study Group. Western Amyotrophic Lateral Sclerosis Study Group. Neurology, 1996, 47(6), 1383-1388.

[175] Miller, R.G.; Moore, D.H., 2nd; Gelinas, D.F.; Dronsky, V.; Mendoza, M.; Barohn, R.J.; Bryan, W.; Ravits, J.; Yuen, E.; Neville, H.; Ringel, S.; Bromberg, M.; Petajan, J.; Amato, A.A.; Jackson, C.; Johnson, W.; Mandler, R.; Bosch, P.; Smith, B.; Graves, M.; Ross, M.; Sorenson, E.J.; Kelkar, P.; Parry, G.; Olney, R. Phase III randomized trial of gabapentin in patients with amyotrophic lateral sclerosis. Neurology, 2001, 56(7), 843-848.

[176] Gordon, P.H. The murky path to drug discovery in ALS becomes clearer. Lancet Neurol., 2013, 12(11), 1037-1038.

[177] Shank, R.P.; Gardocki, J.F.; Streeter, A.J.; Maryanoff, B.E. An overview of the preclinical aspects of topiramate: pharmacology, pharmacokinetics, and mechanism of action. Epilepsia, 2000, 41 Suppl 1, S3-9.

[178] Sachdeo, R.C.; Glauser, T.A.; Ritter, F.; Reife, R.; Lim, P.; Pledger, G. A double-blind, randomized trial of topiramate in Lennox-Gastaut syndrome. Topiramate YL Study Group. Neurology, 1999, 52(9), 1882-1887.
[179] Silberstein, S.D. Topiramate in migraine prevention: evidencebased medicine from clinical trials. Neurol. Sci., 2004, 25 Suppl 3, S244-245.

[180] White, H.S. Molecular pharmacology of topiramate: managing seizures and preventing migraine. Headache, 2005, 45 Suppl 1, S48-56.

[181] Bialer, M.; Johannessen, S.I.; Kupferberg, H.J.; Levy, R.H.; Perucca, E.; Tomson, T. Progress report on new antiepileptic drugs: a summary of the Eigth Eilat Conference (EILAT VIII). Epilepsy Res., 2007, 73(1), 1-52.

[182] Tiihonen, J.; Halonen, P.; Wahlbeck, K.; Repo-Tiihonen, E. Hyvarinen, S.; Eronen, M.; Putkonen, H.; Takala, P.; Mehtonen, O.P.; Puck, M.; Oksanen, J.; Koskelainen, P.; Joffe, G.; Aer, J.; Hallikainen, T.; Ryynanen, O.P.; Tupala, E. Topiramate add-on in treatment-resistant schizophrenia: a randomized, double-blind, placebo-controlled, crossover trial. J. Clin. Psychiatry, 2005, 66(8), 1012-1015.

[183] Van Ameringen, M.; Mancini, C.; Pipe, B.; Oakman, J.; Bennett, M. An open trial of topiramate in the treatment of generalized social phobia. J. Clin. Psychiatry, 2004, 65(12), 1674-1678.

[184] Bartolini, M.; Silvestrini, M.; Taffi, R.; Lanciotti, C.; Luconi, R.; Capecci, M.; Provinciali, L. Efficacy of topiramate and valproate in chronic migraine. Clin. Neuropharmacol., 2005, 28(6), 277-279.

[185] McIntyre, R.S.; Riccardelli, R.; Binder, C.; Kusumakar, V. Openlabel adjunctive topiramate in the treatment of unstable bipolar disorder. Can. J. Psychiatry, 2005, 50(7), 415-422.

[186] Landmark, C.J.; Rytter, E.; Johannessen, S.I. Clinical use of antiepileptic drugs at a referral centre for epilepsy. Seizure, 2007, 16(4), 356-364.

[187] Winum, J.Y.; Scozzafava, A.; Montero, J.L.; Supuran, C.T. Metal binding functions in the design of carbonic anhydrase inhibitors. Curr. Top. Med. Chem., 2007, 7(9), 835-848.

[188] Ghiasi, P.; Hosseinkhani, S.; Noori, A.; Nafissi, S.; Khajeh, K. Mitochondrial complex I deficiency and ATP/ADP ratio in lymphocytes of amyotrophic lateral sclerosis patients. Neurol. Res., 2012, 34(3), 297-303.

[189] Thiry, A.; Dogne, J.M.; Supuran, C.T.; Masereel, B. Carbonic anhydrase inhibitors as anticonvulsant agents. Curr. Top. Med. Chem., 2007, 7(9), 855-864.

[190] Maryanoff, B.E.; Costanzo, M.J.; Nortey, S.O.; Greco, M.N.; Shank, R.P.; Schupsky, J.J.; Ortegon, M.P.; Vaught, J.L. Structureactivity studies on anticonvulsant sugar sulfamates related to topiramate. Enhanced potency with cyclic sulfate derivatives. $J$ Med. Chem., 1998, 41(8), 1315-1343.

[191] Aggarwal, M.; Kondeti, B.; McKenna, R. Anticonvulsant/ antiepileptic carbonic anhydrase inhibitors: a patent review. Expert Opin. Ther. Pat., 2013, 23(6), 717-724.

[192] Brorson, J.R.; Manzolillo, P.A.; Miller, R.J. Ca2+ entry via AMPA/KA receptors and excitotoxicity in cultured cerebellar Purkinje cells. J. Neurosci., 1994, 14(1), 187-197.

[193] Leski, M.L.; Valentine, S.L.; Coyle, J.T. L-type voltage-gated calcium channels modulate kainic acid neurotoxicity in cerebellar granule cells. Brain Res., 1999, 828(1-2), 27-40.

[194] Obrenovitch, T.P.; Urenjak, J. Glutamate release inhibitors: a critical assessment of their action mechanism. Amino Acids, 1998, 14(1-3), 143-150.

[195] Rothman, S.M.; Olney, J.W. Excitotoxicity and the NMDA receptor--still lethal after eight years. Trends Neurosci., 1995, $18(2), 57-58$

[196] Zorumski, C.F.; Olney, J.W. Excitotoxic neuronal damage and neuropsychiatric disorders. Pharmacol. Ther., 1993, 59(2), 145162.

[197] Bialer, M. Chemical properties of antiepileptic drugs (AEDs). Adv. Drug Deliv. Rev., 2012, 64(10), 887-895.

[198] DeLorenzo, R.J.; Sombati, S.; Coulter, D.A. Effects of topiramate on sustained repetitive firing and spontaneous recurrent seizure discharges in cultured hippocampal neurons. Epilepsia, 2000, 41 Suppl. 1, S40-44.

[199] McLean, M.J.; Bukhari, A.A.; Wamil, A.W. Effects of topiramate on sodium-dependent action-potential firing by mouse spinal cord neurons in cell culture. Epilepsia, 2000, 41 Suppl 1, S21-24.

[200] Zona, C.; Ciotti, M.T.; Avoli, M. Topiramate attenuates voltagegated sodium currents in rat cerebellar granule cells. Neurosci. Lett., 1997, 231(3), 123-126.

[201] Taverna, S.; Sancini, G.; Mantegazza, M.; Franceschetti, S.; Avanzini, G. Inhibition of transient and persistent $\mathrm{Na}+$ current 
fractions by the new anticonvulsant topiramate. J. Pharmacol. Exp. Ther., 1999, 288(3), 960-968.

[202] Zhang, X.; Velumian, A.A.; Jones, O.T.; Carlen, P.L. Modulation of high-voltage-activated calcium channels in dentate granule cells by topiramate. Epilepsia, 2000, 41 Suppl 1, S52-60.

[203] Gibbs, J.W., 3rd; Sombati, S.; DeLorenzo, R.J.; Coulter, D.A. Cellular actions of topiramate: blockade of kainate-evoked inward currents in cultured hippocampal neurons. Epilepsia, 2000, 41 Suppl 1, S10-16.

[204] Skradski, S.; White, H.S. Topiramate blocks kainate-evoked cobalt influx into cultured neurons. Epilepsia, 2000, 41 Suppl 1, S45-47.

[205] Angehagen, M.; Ben-Menachem, E.; Ronnback, L.; Hansson, E. Topiramate protects against glutamate- and kainate-induced neurotoxicity in primary neuronal-astroglial cultures. Epilepsy Res., 2003, 54(1), 63-71.

[206] Kaminski, R.M.; Banerjee, M.; Rogawski, M.A. Topiramate selectively protects against seizures induced by ATPA, a GluR5 kainate receptor agonist. Neuropharmacology, 2004, 46(8), 10971104.

[207] Muir, K.W. Glutamate-based therapeutic approaches: clinical trials with NMDA antagonists. Curr. Opin. Pharmacol., 2006, 6(1), 5360 .

[208] Meldrum, B.S. Update on the mechanism of action of antiepileptic drugs. Epilepsia, 1996, 37 Suppl 6, S4-11.

[209] Schroder, W.; Seifert, G.; Huttmann, K.; Hinterkeuser, S.; Steinhauser, C. AMPA receptor-mediated modulation of inward rectifier $\mathrm{K}+$ channels in astrocytes of mouse hippocampus. Mol. Cell. Neurosci., 2002, 19(3), 447-458.

[210] Qian, J.; Noebels, J.L. Topiramate alters excitatory synaptic transmission in mouse hippocampus. Epilepsy Res., 2003, 55(3), 225-233.

[211] White, H.S.; Brown, S.D.; Woodhead, J.H.; Skeen, G.A.; Wolf, H.H. Topiramate modulates GABA-evoked currents in murine cortical neurons by a nonbenzodiazepine mechanism. Epilepsia, 2000, 41 Suppl 1, S17-20.

[212] White, H.S.; Brown, S.D.; Woodhead, J.H.; Skeen, G.A.; Wolf, H.H. Topiramate enhances GABA-mediated chloride flux and GABA-evoked chloride currents in murine brain neurons and increases seizure threshold. Epilepsy Res., 1997, 28(3), 167-179.

[213] Herrero, A.I.; Del Olmo, N.; Gonzalez-Escalada, J.R.; Solis, J.M. Two new actions of topiramate: inhibition of depolarizing GABA(A)-mediated responses and activation of a potassium conductance. Neuropharmacology, 2002, 42(2), 210-220.

[214] De Simone, G.; Scozzafava, A.; Supuran, C.T. Which carbonic anhydrases are targeted by the antiepileptic sulfonamides and sulfamates? Chem. Biol. Drug Des., 2009, 74(3), 317-321.

[215] Maragakis, N.J.; Jackson, M.; Ganel, R.; Rothstein, J.D. Topiramate protects against motor neuron degeneration in organotypic spinal cord cultures but not in G93A SOD1 transgenic mice. Neurosci. Lett., 2003, 338(2), 107-110.

[216] Cudkowicz, M.E.; Shefner, J.M.; Schoenfeld, D.A.; Zhang, H.; Andreasson, K.I.; Rothstein, J.D.; Drachman, D.B. Trial of celecoxib in amyotrophic lateral sclerosis. Ann. Neurol., 2006, 60(1), 22-31.

[217] Desport, J.C.; Preux, P.M.; Truong, T.C.; Vallat, J.M.; Sautereau, D.; Couratier, P. Nutritional status is a prognostic factor for survival in ALS patients. Neurology, 1999, 53(5), 1059-1063.

[218] Nizzardo, M.; Nardini, M.; Ronchi, D.; Salani, S.; Donadoni, C.; Fortunato, F.; Colciago, G.; Falcone, M.; Simone, C.; Riboldi, G.; Govoni, A.; Bresolin, N.; Comi, G.P.; Corti, S. Beta-lactam antibiotic offers neuroprotection in a spinal muscular atrophy model by multiple mechanisms. Exp. Neurol., 2011, 229(2), 214225.

[219] Miller, B.R.; Dorner, J.L.; Shou, M.; Sari, Y.; Barton, S.J.; Sengelaub, D.R.; Kennedy, R.T.; Rebec, G.V. Up-regulation of GLT1 expression increases glutamate uptake and attenuates the Huntington's disease phenotype in the R6/2 mouse. Neuroscience, 2008, 153(1), 329-337.

[220] Chu, K.; Lee, S.T.; Sinn, D.I.; Ko, S.Y.; Kim, E.H.; Kim, J.M.; Kim, S.J.; Park, D.K.; Jung, K.H.; Song, E.C.; Lee, S.K.; Kim, M.; Roh, J.K. Pharmacological Induction of Ischemic Tolerance by Glutamate Transporter-1 (EAAT2) Upregulation. Stroke, 2007, 38(1), 177-182.

[221] Thone-Reineke, C.; Neumann, C.; Namsolleck, P.; Schmerbach, K.; Krikov, M.; Schefe, J.H.; Lucht, K.; Hortnagl, H.; Godes, M.; Muller, S.; Rumschussel, K.; Funke-Kaiser, H.; Villringer, A.;
Steckelings, U.M.; Unger, T. The beta-lactam antibiotic, ceftriaxone, dramatically improves survival, increases glutamate uptake and induces neurotrophins in stroke. J. Hypertens, 2008, 26(12), 2426-2435.

[222] Lipski, J.; Wan, C.K.; Bai, J.Z.; Pi, R.; Li, D.; Donnelly, D. Neuroprotective potential of ceftriaxone in in vitro models of stroke. Neuroscience, 2007, 146(2), 617-629.

[223] Melzer, N.; Meuth, S.G.; Torres-Salazar, D.; Bittner, S.; Zozulya, A.L.; Weidenfeller, C.; Kotsiari, A.; Stangel, M.; Fahlke, C.; Wiendl, H. A beta-lactam antibiotic dampens excitotoxic inflammatory CNS damage in a mouse model of multiple sclerosis. PLoS One, 2008, 3(9), e3149.

[224] Radouane, A.; Pehourcq, F.; Tramu, G.; Creppy, E.E.; Bannwarth, B. Influence of lipophilicity on the diffusion of cephalosporins into the cerebrospinal fluid. Fundam. Clin. Pharmacol., 1996, 10(3), 309-313.

[225] Kim, K.; Lee, S.G.; Kegelman, T.P.; Su, Z.Z.; Das, S.K.; Dash, R.; Dasgupta, S.; Barral, P.M.; Hedvat, M.; Diaz, P.; Reed, J.C.; Stebbins, J.L.; Pellecchia, M.; Sarkar, D.; Fisher, P.B. Role of excitatory amino acid transporter-2 (EAAT2) and glutamate in neurodegeneration: opportunities for developing novel therapeutics. J. Cell. Physiol., 2011, 226(10), 2484-2493.

[226] Jiang, J.; Amara, S.G. New views of glutamate transporter structure and function: advances and challenges. Neuropharmacology, 2011, 60(1), 172-181.

[227] Tian, G.; Lai, L.; Guo, H.; Lin, Y.; Butchbach, M.E.; Chang, Y.; Lin, C.L. Translational control of glial glutamate transporter EAAT2 expression. J. Biol. Chem., 2007, 282(3), 1727-1737.

[228] Dunkel, P.; Chai, C.L.; Sperlagh, B.; Huleatt, P.B.; Matyus, P. Clinical utility of neuroprotective agents in neurodegenerative diseases: current status of drug development for Alzheimer's, Parkinson's and Huntington's diseases, and amyotrophic lateral sclerosis. Expert Opin. Investig. Drugs, 2012, 21(9), 1267-1308.

[229] Glicksman, M.A. The preclinical discovery of amyotrophic lateral sclerosis drugs. Expert Opin. Drug Discov., 2011, 6(11), 11271138.

[230] Vincent, A.M.; Backus, C.; Taubman, A.A.; Feldman, E.L. Identification of candidate drugs for the treatment of ALS. Amyotroph. Lateral. Scler. Other Motor. Neuron Disord., 2005, 6(1), 29-36.

[231] Tikka, T.; Usenius, T.; Tenhunen, M.; Keinanen, R.; Koistinaho, J. Tetracycline derivatives and ceftriaxone, a cephalosporin antibiotic, protect neurons against apoptosis induced by ionizing radiation. $J$. Neurochem., 2001, 78(6), 1409-1414.

[232] Carreer, R.; Deby-Dupont, G.; Deby, C.; Jadoul, L.; Mathy, M. Oxidant-scavenging activities of beta-lactam agents. Eur. J. Clin. Microbiol. Infect. Dis., 1998, 17(1), 43-46.

[233] Ji, H.F.; Shen, L.; Zhang, H.Y. Beta-lactam antibiotics are multipotent agents to combat neurological diseases. Biochem. Biophys. Res. Commun., 2005, 333(3), 661-663.

[234] Karin, M. Nuclear factor-kappaB in cancer development and progression. Nature, 2006, 441(7092), 431-436.

[235] Massa, P.T.; Aleyasin, H.; Park, D.S.; Mao, X.; Barger, S.W. NFkappaB in neurons? The uncertainty principle in neurobiology. J. Neurochem., 2006, 97(3), 607-618.

[236] Su, Z.Z.; Leszczyniecka, M.; Kang, D.C.; Sarkar, D.; Chao, W.; Volsky, D.J.; Fisher, P.B. Insights into glutamate transport regulation in human astrocytes: cloning of the promoter for excitatory amino acid transporter 2 (EAAT2). Proc. Natl. Acad. Sci. USA, 2003, 100(4), 1955-1960.

[237] Sitcheran, R.; Gupta, P.; Fisher, P.B.; Baldwin, A.S. Positive and negative regulation of EAAT2 by NF-kappaB: a role for N-myc in TNFalpha-controlled repression. EMBO J., 2005, 24(3), 510520.

[238] Zelenaia, O.; Schlag, B.D.; Gochenauer, G.E.; Ganel, R.; Song, W.; Beesley, J.S.; Grinspan, J.B.; Rothstein, J.D.; Robinson, M.B. Epidermal growth factor receptor agonists increase expression of glutamate transporter GLT-1 in astrocytes through pathways dependent on phosphatidylinositol 3-kinase and transcription factor NF-kappaB. Mol. Pharmacol., 2000, 57(4), 667-678.

[239] Lee, S.G.; Su, Z.Z.; Emdad, L.; Gupta, P.; Sarkar, D.; Borjabad, A.; Volsky, D.J.; Fisher, P.B. Mechanism of ceftriaxone induction of excitatory amino acid transporter-2 expression and glutamate uptake in primary human astrocytes. J. Biol. Chem., 2008, 283(19), 13116-13123. 
[240] Nau, R.; Prange, H.W.; Muth, P.; Mahr, G.; Menck, S.; Kolenda, H.; Sorgel, F. Passage of cefotaxime and ceftriaxone into cerebrospinal fluid of patients with uninflamed meninges. Antimicrob. Agents Chemother., 1993, 37(7), 1518-1524.

[241] Berry, J.D.; Shefner, J.M.; Conwit, R.; Schoenfeld, D.; Keroack, M.; Felsenstein, D.; Krivickas, L.; David, W.S.; Vriesendorp, F.; Pestronk, A.; Caress, J.B.; Katz, J.; Simpson, E.; Rosenfeld, J.; Pascuzzi, R.; Glass, J.; Rezania, K.; Rothstein, J.D.; Greenblatt, D.J.; Cudkowicz, M.E. Design and initial results of a multi-phase randomized trial of ceftriaxone in amyotrophic lateral sclerosis. PLoS One, 2013, 8(4), e61177.

[242] Chappell, A.S.; Sander, J.W.; Brodie, M.J.; Chadwick, D.; Lledo, A.; Zhang, D.; Bjerke, J.; Kiesler, G.M.; Arroyo, S. A crossover, add-on trial of talampanel in patients with refractory partial seizures. Neurology, 2002, 58(11), 1680-1682.

[243] Langan, Y.M.; Lucas, R.; Jewell, H.; Toublanc, N.; Schaefer, H.; Sander, J.W.; Patsalos, P.N. Talampanel, a new antiepileptic drug: single- and multiple-dose pharmacokinetics and initial 1-week experience in patients with chronic intractable epilepsy. Epilepsia, 2003, 44(1), 46-53.

[244] Czuczwar, S.J.; Swiader, M.; Kuzniar, H.; Gasior, M.; Kleinrok, Z. LY 300164, a novel antagonist of AMPA/kainate receptors, potentiates the anticonvulsive activity of antiepileptic drugs. Eur. $J$. Pharmacol., 1998, 359(2-3), 103-109.

[245] Borowicz, K.K.; Kleinrok, Z.; Czuczwar, S.J. Glutamate receptor antagonists differentially affect the protective activity of conventional antiepileptics against amygdala-kindled seizures in rats. Eur. Neuropsychopharmacol., 2001, 11(1), 61-68.

[246] Howes, J.F.; Bell, C. Talampanel. Neurotherapeutics, 2007, 4(1), 126-129.

[247] Chimirri, A.; De Luca, L.; Ferro, S.; De Sarro, G.; Ciranna, L.; Gitto, R. Combined strategies for the discovery of ionotropic glutamate receptor antagonists. ChemMedChem, 2009, 4(6), 917922.

[248] Gitto, R.; Damiano, F.M.; Mader, P.; De Luca, L.; Ferro, S.; Supuran, C.T.; Vullo, D.; Brynda, J.; Rezacova, P.; Chimirri, A. Synthesis, structure-activity relationship studies, and X-ray crystallographic analysis of arylsulfonamides as potent carbonic anhydrase inhibitors. J. Med. Chem., 2012, 55(8), 3891-3899.

[249] Russo, E.; Gitto, R.; Citraro, R.; Chimirri, A.; De Sarro, G. New AMPA antagonists in epilepsy. Expert Opin. Investig. Drugs, 2012, 21(9), 1371-1389.

[250] Chimirri, A.; De Sarro, G.; De Sarro, A.; Gitto, R.; Quartarone, S.; Zappala, M.; Constanti, A.; Libri, V. 3,5-Dihydro-4H-2,3benzodiazepine-4-thiones: a new class of AMPA receptor antagonists. J. Med. Chem., 1998, 41(18), 3409-3416.

[251] Chimirri, A.; De Sarro, G.; De Sarro, A.; Gitto, R.; Grasso, S.; Quartarone, S.; Zappala, M.; Giusti, P.; Libri, V.; Constanti, A.; Chapman, A.G. 1-Aryl-3,5-dihydro-4H-2,3-benzodiazepin-4-ones: novel AMPA receptor antagonists. J. Med. Chem., 1997, 40(8), 1258-1269.

[252] Ritz, M.; Wang, C.; Micale, N.; Ettari, R.; Niu, L. Mechanism of Inhibition of the GluA2 AMPA Receptor Channel Opening: the Role of 4-Methyl versus 4-Carbonyl Group on the Diazepine Ring of 2,3-Benzodiazepine Derivatives. ACS Chem. Neurosci., 2011, 2(9), 506-513.

[253] Qneibi, M.S.; Micale, N.; Grasso, S.; Niu, L. Mechanism of inhibition of GluA2 AMPA receptor channel opening by 2,3benzodiazepine derivatives: functional consequences of replacing a 7,8-methylenedioxy with a 7,8-ethylenedioxy moiety. Biochemistry, 2012, 51(8), 1787-1795.

[254] Macchiarulo, A.; De Luca, L.; Costantino, G.; Barreca, M.L.; Gitto, R.; Pellicciari, R.; Chimirri, A. QSAR study of anticonvulsant negative allosteric modulators of the AMPA receptor. J. Med. Chem., 2004, 47(7), 1860-1863.

[255] Wang, C.; Niu, L. Mechanism of inhibition of the GluA2 AMPA receptor channel opening by talampanel and its enantiomer: the stereochemistry of the 4-methyl group on the diazepine ring of 2,3benzodiazepine derivatives. ACS Chem. Neurosci., 2013, 4(4), 635644.

[256] Barreca, M.L.; Gitto, R.; Quartarone, S.; De Luca, L.; De Sarro, G.; Chimirri, A. Pharmacophore modeling as an efficient tool in the discovery of novel noncompetitive AMPA receptor antagonists. $J$. Chem. Inf. Comput. Sci., 2003, 43(2), 651-655.
[257] Rezessy, B.; Solyom, S. Advanced Pharmacophore Model of NonCompetitive AMPA Antagonist 2,3-benzodiazepines. Lett. Drug Des. Disc., 2004, 1(3), 217-223.

[258] Cotton, J.L.; Partin, K.M. The contributions of GluR2 to allosteric modulation of AMPA receptors. Neuropharmacology, 2000, 39(1), 21-31.

[259] Elger, B.; Schneider, M.; Winter, E.; Carvelli, L.; Bonomi, M.; Fracasso, C.; Guiso, G.; Colovic, M.; Caccia, S.; Mennini, T. Optimized synthesis of AMPA receptor antagonist ZK 187638 and neurobehavioral activity in a mouse model of neuronal ceroid lipofuscinosis. ChemMedChem, 2006, l(10), 1142-1148.

[260] Tortarolo, M.; Grignaschi, G.; Calvaresi, N.; Zennaro, E.; Spaltro, G.; Colovic, M.; Fracasso, C.; Guiso, G.; Elger, B.; Schneider, H.; Seilheimer, B.; Caccia, S.; Bendotti, C. Glutamate AMPA receptors change in motor neurons of SOD1G93A transgenic mice and their inhibition by a noncompetitive antagonist ameliorates the progression of amytrophic lateral sclerosis-like disease. $J$. Neurosci. Res., 2006, 83(1), 134-146.

[261] Zaccara, G.; Giovannelli, F.; Cincotta, M.; Iudice, A. AMPA receptor inhibitors for the treatment of epilepsy: the role of perampanel. Expert Rev. Neurother., 2013, 13(6), 647-655.

[262] Hsu, W.W.; Sing, C.W.; He, Y.; Worsley, A.J.; Wong, I.C.; Chan, E.W. Systematic review and meta-analysis of the efficacy and safety of perampanel in the treatment of partial-onset epilepsy. CNS Drugs, 2013, 27(10), 817-827.

[263] Bialer, M.; White, H.S. Key factors in the discovery and development of new antiepileptic drugs. Nat. Rev. Drug Discov., 2010, $9(1), 68-82$.

[264] Gitto, R.; Orlando, V.; Quartarone, S.; De Sarro, G.; De Sarro, A.; Russo, E.; Ferreri, G.; Chimirri, A. Synthesis and evaluation of pharmacological properties of novel annelated 2,3-benzodiazepine derivatives. J. Med. Chem., 2003, 46(17), 3758-3761.

[265] Gitto, R.; Barreca, M.L.; De Luca, L.; De Sarro, G.; Ferreri, G.; Quartarone, S.; Russo, E.; Constanti, A.; Chimirri, A. Discovery of a novel and highly potent noncompetitive AMPA receptor antagonist. J. Med. Chem., 2003, 46(1), 197-200.

[266] Sobolevsky, A.I.; Rosconi, M.P.; Gouaux, E. X-ray structure, symmetry and mechanism of an AMPA-subtype glutamate receptor. Nature, 2009, 462(7274), 745-756.

[267] Hogner, A.; Greenwood, J.R.; Liljefors, T.; Lunn, M.L.; Egebjerg, J.; Larsen, I.K.; Gouaux, E.; Kastrup, J.S. Competitive antagonism of AMPA receptors by ligands of different classes: crystal structure of ATPO bound to the GluR2 ligand-binding core, in comparison with DNQX. J. Med. Chem., 2003, 46(2), 214-221.

[268] Menuz, K.; Stroud, R.M.; Nicoll, R.A.; Hays, F.A. TARP auxiliary subunits switch AMPA receptor antagonists into partial agonists. Science, 2007, 318(5851), 815-817.

[269] Armstrong, N.; Gouaux, E. Mechanisms for activation and antagonism of an AMPA-sensitive glutamate receptor: crystal structures of the GluR2 ligand binding core. Neuron, 2000, 28(1), $165-181$

[270] Kaczor, A.A.; Kijkowska-Murak, U.A.; Kronbach, C.; Unverferth, K.; Matosiuk, D. Modeling of glutamate GluR6 receptor and its interactions with novel noncompetitive antagonists. J. Chem. Inf. Model., 2009, 49(4), 1094-1104.

[271] Kaczor, A.A.; Kijkowska-Murak, U.A.; Matosiuk, D. Theoretical studies on the structure and symmetry of the transmembrane region of glutamatergic GluR5 receptor. J. Med. Chem., 2008, 51(13), 3765-3776.

[272] Van Damme, P.; Van Den Bosch, L.; Van Houtte, E.; Callewaert, G.; Robberecht, W. GluR2-dependent properties of AMPA receptors determine the selective vulnerability of motor neurons to excitotoxicity. J. Neurophysiol., 2002, 88(3), 1279-1287.

[273] Vandenberghe, W.; Robberecht, W.; Brorson, J.R. AMPA receptor calcium permeability, GluR2 expression, and selective motoneuron vulnerability. J. Neurosci., 2000, 20(1), 123-132.

[274] Van Den Bosch, L.; Vandenberghe, W.; Klaassen, H.; Van Houtte, E.; Robberecht, W. $\mathrm{Ca}(2+)$-permeable AMPA receptors and selective vulnerability of motor neurons. J. Neurol. Sci., 2000, 180(1-2), 29-34.

[275] De Sarro, G.; Gitto, R.; Russo, E.; Ibbadu, G.F.; Barreca, M.L.; De Luca, L.; Chimirri, A. AMPA receptor antagonists as potential anticonvulsant drugs. Curr. Top. Med. Chem., 2005, 5(1), 31-42.

[276] Solyom, S. Research on new AMPA antagonists of 2,3benzodiazepine type. Pharmazie, 2001, 56 Suppl 1, S62-66. 
[277] Denes, L.; Szilagyi, G.; Gal, A.; Nagy, Z. Talampanel a noncompetitive AMPA-antagonist attenuates caspase-3 dependent apoptosis in mouse brain after transient focal cerebral ischemia. Brain Res. Bull., 2006, 70(3), 260-262.

[278] Canton, T.; Bohme, G.A.; Boireau, A.; Bordier, F.; Mignani, S.; Jimonet, P.; Jahn, G.; Alavijeh, M.; Stygall, J.; Roberts, S.; Brealey, C.; Vuilhorgne, M.; Debono, M.W.; Le Guern, S.; Laville, M.; Briet, D.; Roux, M.; Stutzmann, J.M.; Pratt, J. RPR 119990, a novel alpha-amino-3-hydroxy-5-methyl-4-isoxazolepropionic acid antagonist: synthesis, pharmacological properties, and activity in an animal model of amyotrophic lateral sclerosis. J. Pharmacol. Exp. Ther., 2001, 299(1), 314-322.

[279] Van Damme, P.; Leyssen, M.; Callewaert, G.; Robberecht, W.; Van Den Bosch, L. The AMPA receptor antagonist NBQX prolongs survival in a transgenic mouse model of amyotrophic lateral sclerosis. Neurosci. Lett., 2003, 343(2), 81-84.

[280] Pascuzzi, R.M.; Shefner, J.; Chappell, A.S.; Bjerke, J.S.; Tamura, R.; Chaudhry, V.; Clawson, L.; Haas, L.; Rothstein, J.D. A phase II trial of talampanel in subjects with amyotrophic lateral sclerosis. Amyotroph. Lateral. Scler., 2010, 11(3), 266-271.

[281] Gerzon, K.; Krumkalns, E.V.; Brindle, R.L.; Marshall, F.J.; Root, M.A. The Adamantyl Group in Medicinal Agents. I. Hypoglycemic N-Arylsulfonyl-N' -Adamantylureas. J. Med. Chem., 1963, 6, 760763.

[282] Parsons, C.G.; Danysz, W.; Quack, G. Memantine is a clinically well tolerated N-methyl-D-aspartate (NMDA) receptor antagonist-a review of preclinical data. Neuropharmacology, 1999, 38(6), 735767.

[283] Bormann, J. Memantine is a potent blocker of N-methyl-Daspartate (NMDA) receptor channels. Eur. J. Pharmacol., 1989, 166(3), 591-592.

[284] Kornhuber, J.; Bormann, J.; Retz, W.; Hubers, M.; Riederer, P. Memantine displaces [3H]MK-801 at therapeutic concentrations in postmortem human frontal cortex. Eur. J. Pharmacol., 1989, 166(3), 589-590.

[285] Kornhuber, J.; Bormann, J.; Hubers, M.; Rusche, K.; Riederer, P. Effects of the 1-amino-adamantanes at the MK-801-binding site of the NMDA-receptor-gated ion channel: a human postmortem brain study. Eur. J. Pharmacol., 1991, 206(4), 297-300.

[286] Parsons, C.G.; Gruner, R.; Rozental, J.; Millar, J.; Lodge, D. Patch clamp studies on the kinetics and selectivity of N-methyl-Daspartate receptor antagonism by memantine (1-amino-3,5dimethyladamantan). Neuropharmacology, 1993, 32(12), 13371350 .

[287] Parsons, C.G.; Quack, G.; Bresink, I.; Baran, L.; Przegalinski, E.; Kostowski, W.; Krzascik, P.; Hartmann, S.; Danysz, W. Comparison of the potency, kinetics and voltage-dependency of a series of uncompetitive NMDA receptor antagonists in vitro with anticonvulsive and motor impairment activity in vivo. Neuropharmacology, 1995, 34(10), 1239-1258.

[288] Jain, K.K. Evaluation of memantine for neuroprotection in dementia. Expert Opin. Investig. Drugs, 2000, 9(6), 1397-1406.

[289] Sonkusare, S.K.; Kaul, C.L.; Ramarao, P. Dementia of Alzheimer's disease and other neurodegenerative disorders--memantine, a new hope. Pharmacol. Res., 2005, 51(1), 1-17.

[290] Schmitt, H.P. On the paradox of ion channel blockade and its benefits in the treatment of Alzheimer disease. Med. Hypotheses, 2005, 65(2), 259-265.

[291] Lipton, S.A. Paradigm shift in neuroprotection by NMDA receptor blockade: memantine and beyond. Nat. Rev. Drug Discov., 2006, 5(2), 160-170.

[292] Parsons, C.G.; Stoffler, A.; Danysz, W. Memantine: a NMDA receptor antagonist that improves memory by restoration of homeostasis in the glutamatergic system--too little activation is bad, too much is even worse. Neuropharmacology, 2007, 53(6), 699-723.

[293] Zdanys, K.; Tampi, R.R. A systematic review of off-label uses of memantine for psychiatric disorders. Prog. Neuropsycho pharmacol. Biol. Psychiatry, 2008, 32(6), 1362-1374.

[294] Kornhuber, J.; Quack, G. Cerebrospinal fluid and serum concentrations of the N-methyl-D-aspartate (NMDA) receptor antagonist memantine in man. Neurosci. Lett., 1995, 195(2), 137139.

[295] Johnson, J.W.; Kotermanski, S.E. Mechanism of action of memantine. Curr. Opin. Pharmacol., 2006, 6(1), 61-67.
[296] Long, S.B.; Tao, X.; Campbell, E.B.; MacKinnon, R. Atomic structure of a voltage-dependent $\mathrm{K}+$ channel in a lipid membranelike environment. Nature, 2007, 450(7168), 376-382.

[297] Kashiwagi, K.; Masuko, T.; Nguyen, C.D.; Kuno, T.; Tanaka, I.; Igarashi, K.; Williams, K. Channel blockers acting at N-methylD-aspartate receptors: differential effects of mutations in the vestibule and ion channel pore. Mol. Pharmacol., 2002, 61(3), 533-545

[298] Limapichat, W.; Yu, W.Y.; Branigan, E.; Lester, H.A.; Dougherty, D.A. Key binding interactions for memantine in the NMDA receptor. ACS Chem. Neurosci., 2013, 4(2), 255-260.

[299] Jirgensons, A.; Kauss, V.; Kalvinsh, I.; Gold, M.R.; Danysz, W.; Parsons, C.G.; Quack, G. Synthesis and structure-affinity relationships of 1,3,5-alkylsubstituted cyclohexylamines binding at NMDA receptor PCP site. Eur. J. Med. Chem., 2000, 35(6), 555565 .

[300] Wong, E.H.; Kemp, J.A.; Priestley, T.; Knight, A.R.; Woodruff, G.N.; Iversen, L.L. The anticonvulsant MK-801 is a potent Nmethyl-D-aspartate antagonist. Proc. Natl. Acad. Sci. USA, 1986, 83(18), 7104-7108.

[301] Huettner, J.E.; Baughman, R.W. The pharmacology of synapses formed by identified corticocollicular neurons in primary cultures of rat visual cortex. J. Neurosci., 1988, 8(1), 160-175.

[302] Fultz, T.J.; Wang, Y. Therapeutic conjugates and methods of using same, WO2007065036 A3, 2007.

[303] Furukawa, H.; Singh, S.K.; Mancusso, R.; Gouaux, E. Subunit arrangement and function in NMDA receptors. Nature, $\mathbf{2 0 0 5}$, 438(7065), 185-192.

[304] Rogawski, M.A.; Wenk, G.L. The neuropharmacological basis for the use of memantine in the treatment of Alzheimer's disease. CNS Drug Rev., 2003, 9(3), 275-308.

[305] Parsons, C.G.; Gilling, K. Memantine as an example of a fast, voltage-dependent, open channel N-methyl-D-aspartate receptor blocker. Methods Mol. Biol., 2007, 403, 15-36.

[306] Robinson, K.M.; Lacey, S.C.; Grugan, P.; Glosser, G.; Grossman, M.; McCluskey, L.F. Cognitive functioning in sporadic amyotrophic lateral sclerosis: a six month longitudinal study. $J$. Neurol. Neurosurg. Psychiatry, 2006, 77(5), 668-670.

[307] McKay, S.; Bengtson, C.P.; Bading, H.; Wyllie, D.J.; Hardingham, G.E. Recovery of NMDA receptor currents from MK-801 blockade is accelerated by $\mathrm{Mg} 2+$ and memantine under conditions of agonist exposure. Neuropharmacology, 2013, 74, 119-125.

[308] Chen, H.S.; Lipton, S.A. Pharmacological implications of two distinct mechanisms of interaction of memantine with N-methyl-Daspartate-gated channels. J. Pharmacol. Exp. Ther., 2005, 314(3), 961-971.

[309] Sobolevsky, A.I.; Koshelev, S.G.; Khodorov, B.I. Interaction of memantine and amantadine with agonist-unbound NMDA-receptor channels in acutely isolated rat hippocampal neurons. J. Physiol., 1998, 512 ( Pt 1), 47-60.

[310] Kotermanski, S.E.; Wood, J.T.; Johnson, J.W. Memantine binding to a superficial site on NMDA receptors contributes to partial trapping. J. Physiol., 2009, 587(Pt 19), 4589-4604.

[311] Robinson, D.M.; Keating, G.M. Memantine: a review of its use in Alzheimer's disease. Drugs, 2006, 66(11), 1515-1534.

[312] Tomek, S.E.; Lacrosse, A.L.; Nemirovsky, N.E.; Olive, M.F. NMDA Receptor Modulators in the Treatment of Drug Addiction. Pharmaceuticals (Basel.), 2013, 6(2), 251-268.

[313] Chen, H.S.; Lipton, S.A. The chemical biology of clinically tolerated NMDA receptor antagonists. J. Neurochem., 2006, 97(6), 1611-1626.

[314] Chen, H.S.; Pellegrini, J.W.; Aggarwal, S.K.; Lei, S.Z.; Warach, S.; Jensen, F.E.; Lipton, S.A. Open-channel block of N-methyl-Daspartate (NMDA) responses by memantine: therapeutic advantage against NMDA receptor-mediated neurotoxicity. J. Neurosci., 1992, 12(11), 4427-4436.

[315] Kotermanski, S.E.; Johnson, J.W. Mg2+ imparts NMDA receptor subtype selectivity to the Alzheimer's drug memantine. $J$ Neurosci., 2009, 29(9), 2774-2779.

[316] Olive, M.F.; Cleva, R.M.; Kalivas, P.W.; Malcolm, R.J. Glutamatergic medications for the treatment of drug and behavioral addictions. Pharmacol. Biochem. Behav., 2012, 100(4), 801-810.

[317] Aracava, Y.; Pereira, E.F.; Maelicke, A.; Albuquerque, E.X. Memantine blocks alpha $7 *$ nicotinic acetylcholine receptors more 
potently than n-methyl-D-aspartate receptors in rat hippocampal neurons. J. Pharmacol. Exp. Ther., 2005, 312(3), 1195-1205.

[318] Snyder, E.M.; Nong, Y.; Almeida, C.G.; Paul, S.; Moran, T.; Choi, E.Y.; Nairn, A.C.; Salter, M.W.; Lombroso, P.J.; Gouras, G.K.; Greengard, P. Regulation of NMDA receptor trafficking by amyloid-beta. Nat. Neurosci., 2005, 8(8), 1051-1058.

[319] Li, L.; Sengupta, A.; Haque, N.; Grundke-Iqbal, I.; Iqbal, K. Memantine inhibits and reverses the Alzheimer type abnormal hyperphosphorylation of tau and associated neurodegeneration. FEBS Lett., 2004, 566(1-3), 261-269.

[320] Murayama, S.; Mori, H.; Ihara, Y.; Bouldin, T.W.; Suzuki, K.; Tomonaga, M. Immunocytochemical and ultrastructural studies of lower motor neurons in amyotrophic lateral sclerosis. Ann. Neurol., 1990, 27(2), 137-148.

[321] Brettschneider, J.; Petzold, A.; Sussmuth, S.D.; Ludolph, A.C.; Tumani, H. Axonal damage markers in cerebrospinal fluid are increased in ALS. Neurology, 2006, 66(6), 852-856.

[322] Jimenez-Jimenez, F.J.; Hernanz, A.; Medina-Acebron, S.; de Bustos, F.; Zurdo, J.M.; Alonso, H.; Puertas, I.; Barcenilla, B.; Sayed, Y.; Cabrera-Valdivia, F. Tau protein concentrations in cerebrospinal fluid of patients with amyotrophic lateral sclerosis. Acta Neurol. Scand., 2005, 111(2), 114-117.

[323] Levine, T.D.; Bowser, R.; Hank, N.; Saperstein, D. A pilot trial of memantine and riluzole in ALS: correlation to CSF biomarkers. Amyotroph. Lateral. Scler., 2010, 11(6), 514-519.

[324] Osborne, N.N.; Quack, G. Memantine stimulates inositol phosphates production in neurones and nullifies N-methyl-Daspartate-induced destruction of retinal neurones. Neurochem. Int., 1992, 21(3), 329-336.

[325] Lampe, H.; Bigalke, H. Modulation of glycine-activated membrane current by adamantane derivatives. Neuroreport, 1991, 2(7), 373376.

[326] Wenk, G.L.; Zajaczkowski, W.; Danysz, W. Neuroprotection of acetylcholinergic basal forebrain neurons by memantine and neurokinin B. Behav. Brain Res., 1997, 83(1-2), 129-133.

[327] Miguel-Hidalgo, J.J.; Alvarez, X.A.; Cacabelos, R.; Quack, G. Neuroprotection by memantine against neurodegeneration induced by beta-amyloid(1-40). Brain Res., 2002, 958(1), 210-221.

[328] Wang, R.; Zhang, D. Memantine prolongs survival in an amyotrophic lateral sclerosis mouse model. Eur. J. Neurosci., 2005, 22(9), 2376-2380.

[329] Joo, I.S.; Hwang, D.H.; Seok, J.I.; Shin, S.K.; Kim, S.U. Oral administration of memantine prolongs survival in a transgenic mouse model of amyotrophic lateral sclerosis. J. Clin. Neurol., 2007, 3(4), 181-186.

[330] de Carvalho, M.; Pinto, S.; Costa, J.; Evangelista, T.; Ohana, B.; Pinto, A. A randomized, placebo-controlled trial of memantine for functional disability in amyotrophic lateral sclerosis. Amyotroph. Lateral. Scler., 2010, 11(5), 456-460.

[331] Reid, J.G.; Gitlin, M.J.; Altshuler, L.L. Lamotrigine in psychiatric disorders. J. Clin. Psychiatry, 2013, 74(7), 675-684.

[332] Vajda, F.J.; Dodd, S.; Horgan, D. Lamotrigine in epilepsy, pregnancy and psychiatry--a drug for all seasons? J. Clin. Neurosci., 2013, 20(1), 13-16.

[333] Leach, M.J.; Marden, C.M.; Miller, A.A. Pharmacological studies on lamotrigine, a novel potential antiepileptic drug: II. Neurochemical studies on the mechanism of action. Epilepsia, 1986, 27(5), 490-497.

[334] Knowles, S.R.; Shapiro, L.E.; Shear, N.H. Anticonvulsant hypersensitivity syndrome: incidence, prevention and management. Drug Saf., 1999, 21(6), 489-501.

[335] Wang, X.Q.; Shi, X.B.; Au, R.; Chen, F.S.; Wang, F.; Lang, S.Y. Influence of chemical structure on skin reactions induced by antiepileptic drugs-The role of the aromatic ring. Epilepsy Res., 2011, 94(3), 213-217.

[336] Kuo, C.C. A common anticonvulsant binding site for phenytoin, carbamazepine, and lamotrigine in neuronal $\mathrm{Na}+$ channels. Mol. Pharmacol., 1998, 54(4), 712-721.

[337] Ma, X.; Poon, T.Y.; Wong, P.T.; Chui, W.K. Synthesis and in vitro evaluation of 2,4-diamino-1,3,5-triazine derivatives as neuronal voltage-gated sodium channel blockers. Bioorg. Med. Chem. Lett., 2009, 19(19), 5644-5647.

[338] Kaushik, D.; Khan, S.A.; Chawla, G.; Kumar, S. N'-[(5-chloro-3methyl-1-phenyl-1H-pyrazol-4-yl)methylene] 2/4-substituted hydrazides: synthesis and anticonvulsant activity. Eur. J. Med. Chem., 2010, 45(9), 3943-3949.
[339] Ding, H.G.; Wang, B.E.; Zhao, C.H.; Jia, J.D.; Xu, Y.L.; Tang, S.Z. Effects on intracellular $\mathrm{Ca} 2+$ and expression of L-type voltage-operated calcium channel protein in activated hepatic stellate cells stimulated by Chinese herbal compound 861 . Zhonghua Gan Zang Bing Za Zhi, 2005, 13(12), 922-926.

[340] Cronin, N.B.; O'Reilly, A.; Duclohier, H.; Wallace, B.A. Binding of the anticonvulsant drug lamotrigine and the neurotoxin batrachotoxin to voltage-gated sodium channels induces conformational changes associated with block and steady-state activation. J. Biol. Chem., 2003, 278(12), 10675-10682.

[341] Yarov-Yarovoy, V.; Brown, J.; Sharp, E.M.; Clare, J.J.; Scheuer, T.; Catterall, W.A. Molecular determinants of voltage-dependent gating and binding of pore-blocking drugs in transmembrane segment IIIS6 of the $\mathrm{Na}(+)$ channel alpha subunit. J. Biol. Chem., 2001, 276(1), 20-27.

[342] Xie, X.; Dale, T.J.; John, V.H.; Cater, H.L.; Peakman, T.C.; Clare, J.J. Electrophysiological and pharmacological properties of the human brain type IIA $\mathrm{Na}+$ channel expressed in a stable mammalian cell line. Pflugers Arch., 2001, 441(4), 425-433.

[343] Reynolds, E.H., Anticonvulsants, folic acid, and epilepsy. Lancet, 1973, $1(7816), 1376-1378$

[344] Lingamaneni, R.; Hemmings, H.C., Jr. Effects of anticonvulsants on veratridine- and $\mathrm{KCl}$-evoked glutamate release from rat cortical synaptosomes. Neurosci. Lett., 1999, 276(2), 127-130.

[345] Fitton, A.; Goa, K.L. Lamotrigine. An update of its pharmacology and therapeutic use in epilepsy. Drugs, 1995, 50(4), 691-713.

[346] Wang, S.J.; Sihra, T.S.; Gean, P.W. Lamotrigine inhibition of glutamate release from isolated cerebrocortical nerve terminals (synaptosomes) by suppression of voltage-activated calcium channel activity. Neuroreport, 2001, 12(10), 2255-2258.

[347] Sitges, M.; Guarneros, A.; Nekrassov, V. Effects of carbamazepine, phenytoin, valproic acid, oxcarbazepine, lamotrigine, topiramate and vinpocetine on the presynaptic $\mathrm{Ca} 2+$ channel-mediated release of $[3 \mathrm{H}]$ glutamate: comparison with the $\mathrm{Na}+$ channel-mediated release. Neuropharmacology, 2007, 53(7), 854-862.

[348] Sitges, M.; Chiu, L.M.; Guarneros, A.; Nekrassov, V. Effects of carbamazepine, phenytoin, lamotrigine, oxcarbazepine, topiramate and vinpocetine on $\mathrm{Na}+$ channel-mediated release of $[3 \mathrm{H}]$ glutamate in hippocampal nerve endings. Neuropharmacology, 2007, 52(2), 598-605.

[349] Li, X.; Ketter, T.A.; Frye, M.A. Synaptic, intracellular, and neuroprotective mechanisms of anticonvulsants: are they relevant for the treatment and course of bipolar disorders? J. Affect. Disord., 2002, 69(1-3), 1-14

[350] Stefani, A.; Spadoni, F.; Bernardi, G. Differential inhibition by riluzole, lamotrigine, and phenytoin of sodium and calcium currents in cortical neurons: implications for neuroprotective strategies. Exp. Neurol., 1997, 147(1), 115-122.

[351] Phillips, I.; Martin, K.F.; Thompson, K.S.; Heal, D.J. Weak blockade of AMPA receptor-mediated depolarisations in the rat cortical wedge by phenytoin but not lamotrigine or carbamazepine. Eur. J. Pharmacol., 1997, 337(2-3), 189-195.

[352] Lee, C.Y.; Fu, W.M.; Chen, C.C.; Su, M.J.; Liou, H.H. Lamotrigine inhibits postsynaptic AMPA receptor and glutamate release in the dentate gyrus. Epilepsia, 2008, 49(5), 888-897.

[353] Casanovas, A.; Ribera, J.; Hukkanen, M.; Riveros-Moreno, V.; Esquerda, J.E. Prevention by lamotrigine, MK-801 and N omeganitro-L-arginine methyl ester of motoneuron cell death after neonatal axotomy. Neuroscience, 1996, 71(2), 313-325.

[354] Ryberg, H.; Askmark, H.; Persson, L.I. A double-blind randomized clinical trial in amyotrophic lateral sclerosis using lamotrigine: effects on CSF glutamate, aspartate, branched-chain amino acid levels and clinical parameters. Acta Neurol. Scand., 2003, 108(1), $1-8$.

[355] Eriksson, A.S.; O'Connor, W.T. Analysis of CSF amino acids in young patients with generalised refractory epilepsy during an addon study with lamotrigine. Epilepsy Res., 1999, 34(1), 75-83.

[356] Lunn, J.S.; Sakowski, S.A.; Feldman, E.L. Stem cell therapies for amyotrophic lateral sclerosis: Recent advances and prospects for the future. Stem Cells, 2014, 32(5), 1099-1109.

[357] Navarro-Yepes, J.; Zavala-Flores, L.; Anandhan, A.; Wang, F.; Skotak, M.; Chandra, N.; Li, M.; Pappa, A.; Martinez-Fong, D.; Del Razo, L.M.; Quintanilla-Vega, B.; Franco, R. Antioxidant gene therapy against neuronal cell death. Pharmacol. Ther., 2013, 142(2), 206-230. 
[358] Geldenhuys, W.J.; Van der Schyf, C.J. Designing drugs with multitarget activity: the next step in the treatment of neurodegenerative disorders. Expert Opin. Drug Discov., 2013, 8(2), 115-129.

[359] Otto, M.; Bowser, R.; Turner, M.; Berry, J.; Brettschneider, J.; Connor, J.; Costa, J.; Cudkowicz, M.; Glass, J.; Jahn, O.; Lehnert, S.; Malaspina, A.; Parnetti, L.; Petzold, A.; Shaw, P.; Sherman, A.; Steinacker, P.; Sussmuth, S.; Teunissen, C.;
Tumani, H.; Wuolikainen, A.; Ludolph, A. Roadmap and standard operating procedures for biobanking and discovery of neurochemical markers in ALS. Amyotroph. Lateral. Scler., 2012, 13(1), 1-10.

[360] Trushina, E.; Mielke, M.M. Recent advances in the application of metabolomics to Alzheimer's Disease. Biochim. Biophys. Acta, 2014, $1842(8), 1232-1239$. 